\title{
LKB1-Mediated Spatial Control of GSK3 $\beta$ and Adenomatous Polyposis Coli Contributes to Centrosomal Forward Movement and Neuronal Migration in the Developing Neocortex
}

\author{
Naoyuki Asada ${ }^{1}$ and Kamon Sanada ${ }^{1,2}$ \\ ${ }^{1}$ Molecular Genetics Research Laboratory, Graduate School of Science, The University of Tokyo, Bunkyo-ku, Tokyo 113-0033, Japan, and 2Precursory \\ Research for Embryonic Science and Technology, Japan Science and Technology Agency, Kawaguchi, Saitama 332-0012, Japan
}

\begin{abstract}
Neuronal migration is an essential process for the development of the cerebral cortex. We have previously shown that LKB1, an evolutionally conserved polarity kinase, plays a critical role in neuronal migration in the developing neocortex. Here we show that LKB1 mediates Ser9 phosphorylation of GSK3 $\beta$ to inactivate the kinase at the leading process tip of migrating neurons in the developing neocortex. This enables the microtubule plus-end binding protein adenomatous polyposis coli (APC) to localize at the distal ends of microtubules in the tip, thereby stabilizing microtubules near the leading edge. We also show that LKB1 activity, Ser9 phosphorylation of GSK $3 \beta$, and APC binding to the distal ends of microtubules are required for the microtubule stabilization in the leading process tip, centrosomal forward movement, and neuronal migration. These findings suggest that LKB1-induced spatial control of GSK3 $\beta$ and APC at the leading process tip mediates the stabilization of microtubules within the tip and is critical for centrosomal forward movement and neuronal migration in the developing neocortex.
\end{abstract}

\section{Introduction}

The formation of the cerebral cortex is achieved by radial migration of postmitotic neurons from their birthplace in the ventricular zone toward the pial surface. As cortical neurons migrate along fibers of radial glia to reach their destination (Hatten, 1990; Rakic, 1990), they undergo a series of highly organized cellular events, including leading process extension toward the direction of migration, centrosomal movement toward the leading process tip, and nuclear translocation toward the centrosome (Solecki et al., 2004; Tanaka et al., 2004; Tsai and Gleeson, 2005). These subcellular behaviors require the establishment of cell polarity, mediated itself by the asymmetric distribution and regulation of cytoskeletal proteins. For instance, the microtubule network linking the centrosome to the nucleus is maintained by several centrosomal and/or microtubule-associated proteins, such as Lis1, DCX, and FAK, and is key for the nuclear translocation to the centrosome (Xie et al., 2003; Tanaka et al., 2004). At the

\footnotetext{
Received Dec. 11, 2009; revised May 6, 2010; accepted May 15, 2010.

This work is supported in part by a Grant-in-Aid for Scientific Research (B) (to K.S.) from the Japanese Ministry of Education, Culture, Sports, Science and Technology. N.A. is supported by Japan Society for the Promotion of Science Research Fellowships for Young Scientists. We thank Dr. Takahiko Matsuda for the pCAG-IRES-GFP plasmid, Dr. Yang Shi for the pBS-U6 plasmid, Dr. Yukiko Gotoh for the Human GSK3 $\beta$ (S9A)-expressing plasmid, and Dr. Yuko Kiyosue for the Xenopus APC-expressing plasmids. We are also grateful to Dr. Minh Dang Nguyen for critical reading of this manuscript.

Correspondence should be addressed to Dr. Kamon Sanada, Molecular Genetics Research Laboratory, Graduate School of Science, The University of Tokyo, Hongo 7-3-1, Bunkyo-ku, Tokyo 113-0033, Japan. E-mail: kamon_sanada@gen.s.u-tokyo.ac.jp.

DOI:10.1523/JNEUROSCI.6140-09.2010

Copyright $\odot 2010$ the authors $\quad 0270-6474 / 10 / 308852-14 \$ 15.00 / 0$
}

leading process tip, the actin cytoskeleton is rearranged during neuronal migration, which may contribute to leading process extension (Walsh and Goffinet, 2000; Lambert de Rouvroit and Goffinet, 2001). In addition, F-actin and its motor Myosin II, both concentrated near the centrosome, contribute to the coordinated movement of the centrosome and nucleus (Solecki et al., 2009).

Recent studies underscore the role of evolutionally conserved polarity proteins such as Par (Partitioning defective) in neuronal migration. Par6 $\alpha$, LKB1 (also known as Par4), and MARK2 (Par1) were originally identified as key regulators of the anterior/ posterior axis in one-cell embryos of Caenorhabditis elegans. In addition, these proteins establish polarity in various cell types from diverse organisms (Kemphues et al., 1988; Goldstein and Macara, 2007). Noticeably, LKB1 and MARK2 are essential for neuronal migration in the developing neocortex (Asada et al., 2007; Sapir et al., 2008), and Par6 $\alpha$ in migrating cerebellar granular neurons (Solecki et al., 2004). Although Par proteinmediated polarity signaling likely regulates neuronal migration, little is known about the signaling pathways and their subcellular roles in migrating neurons.

In the present study, we show that LKB1 mediates Ser9 phosphorylation of glycogen synthase kinase $3 \beta$ (GSK3 $\beta$ ) and inactivates it at the leading process tip of migrating neurons in the developing neocortex. The inactivation of GSK3 $\beta$ allows adenomatous polyposis coli (APC), a microtubule-anchoring protein, to localize at the distal ends of microtubules in the leading process tip, and this consequently leads to microtubule stabilization in the region. Importantly, disruption of either LKB1 activity, Ser9 
phosphorylation of GSK3 $\beta$, or APC localization at the microtubule plus-ends causes microtubule destabilization in the leading process tip. Ultimately, this causes retardation of the centrosomal forward movement and neuronal migration defects. Altogether, we illustrate a model in which LKB1-mediated localized inactivation of GSK $3 \beta$ and the subsequent APC binding to the microtubule plus-ends at the tip of the leading process leads to the microtubule capture and stabilization, which contributes to pulling of the centrosome up within the leading process of migrating neurons. Our study unravels the importance of LKB1-controlled signaling in the polarization of microtubules and centrosomal forward movement required for neuronal migration.

\section{Materials and Methods}

Plasmids. The pCAGEN and pCAG-IRES-GFP plasmids were kindly provided by T. Matsuda (Harvard Medical School, Boston, MA). Human GSK $3 \beta$ S9A in the pCS4 plasmid was kindly provided by Y. Gotoh (University of Tokyo, Tokyo, Japan), and the plasmid coexpressing GSK3 $\beta$ S9A and GFP (pCAG-GSK3 $\beta$ S9A-IRES-GFP plasmid) was generated by subcloning of the open reading frame (ORF) of GSK3 $\beta$ S9A into the pCAG-IRES-GFP plasmid, which directs subcloned gene expression from the CAG promoter and EGFP expression through the internal ribosomal entry site. The plasmids encoding full-length and C-terminaldeleted mutant of Xenopus APC were kindly provided by Y. Kiyosue (KAN Research Institute, Kobe, Japan). The RNAi vector for mouse LKB1 was generated as described previously (Asada et al., 2007). The target sequence for LKB1 RNAi was as follows: 5'-GGGTCAGAATGGACAGAGCCA-3' (Asada et al., 2007).

Cell culture, transfection, coimmunoprecipitation, and kinase assay. HEK293T cells were maintained in DMEM with 10\% fetal bovine serum (FBS) and antibiotics. Plasmids were transfected into HEK293T cells using Lipofectamine 2000 (Invitrogen). After $48 \mathrm{~h}$ incubation, cells were lysed in lysis buffer [20 mm HEPES, $100 \mathrm{~mm} \mathrm{NaCl}, 1.0 \%$ Triton X-100, 10 mм NaF, $2 \mathrm{~mm} \mathrm{Na}_{3} \mathrm{VO}_{4}$, and protease inhibitor cocktail (Complete, EDTA-free; Roche Molecular Biochemicals); pH 7.4]. Following 15 min incubation on ice, the cell lysates were centrifuged for $15 \mathrm{~min}$ at $20,000 \times$ $\mathrm{g}$, and the resultant supernatant was collected. The cell extracts were then precleared by incubation with $20 \mu$ l of Protein G-Sepharose (GE Healthcare) for $30 \mathrm{~min}$, and incubated with goat anti-LKB1 antibody ( $2 \mu \mathrm{g}$; D-19; Santa Cruz Biotechnology) or mouse anti-GFP antibody $(2 \mu \mathrm{g}$; clone $1 \mathrm{E} 4$; MBL) for $24 \mathrm{~h}$ at $4^{\circ} \mathrm{C}$, followed by incubation with $20 \mu \mathrm{l}$ of Protein G-Sepharose for 3-4 h. For coimmunoprecipitation assay, the beads were washed four times with the lysis buffer and were then subjected to immunoblotting (Asada et al., 2007). For immunoprecipitation-kinase assay (IP-kinase assay), the beads were washed three times with the lysis buffer and then washed once with the Triton X-100free lysis buffer. The resultant immunoprecipitate was mixed with the 8 $\mu \mathrm{l}$ of recombinant GSK $3 \beta$ (New England Biolabs) $(0.01 \mu \mathrm{g})$ and $12 \mu \mathrm{l}$ of GSK-3 reaction buffer (New England Biolabs) (final $1 \times$ concentration) supplemented with ATP (final concentration, $1 \mathrm{~mm}$ ), NaF (10 mM), $\mathrm{Na}_{3} \mathrm{VO}_{4}(2 \mathrm{~mm})$, and protease inhibitor cocktail (Complete, EDTA-free). After $30 \mathrm{~min}$ incubation at $30^{\circ} \mathrm{C}$, the mixture was subjected to immunoblotting (Asada et al., 2007). Before using recombinant GSK3 $\beta$ in the assay, GSK $3 \beta$ was treated with protein phosphatase 1 (PP1) $(10 \mathrm{U} / \mu \mathrm{g}$ of GSK3 $\beta$ ) (New England Biolabs) in NEBuffer for PMP (New England Biolabs) supplemented with $\mathrm{MnCl}_{2}$ (final concentration, $1 \mathrm{~mm}$ ) and protease inhibitor cocktail (Complete, EDTA-free) for $60 \mathrm{~min}$ at $30^{\circ} \mathrm{C}$. The reaction was then terminated by the addition of protein phosphatase inhibitor 2 (I-2) (New England Biolabs) (final concentration, $1 \mu \mathrm{M}$ ) and incubated for $15 \mathrm{~min}$ before the IP-kinase assay.

For in vivo binding assay, forebrains were dissected out from embryonic day 16 (E16) mouse embryos (total 14 brains), followed by homogenization with the lysis buffer. Following $15 \mathrm{~min}$ incubation on ice, the brain homogenates were centrifuged for $10 \mathrm{~min}$ at 20,000 $\times \mathrm{g}$, and the resultant supernatant was collected. The brain extracts were then precleared by incubation with $25 \mu \mathrm{l}$ of Protein G-Sepharose for $30 \mathrm{~min}$, and incubated with goat anti-LKB1 antibody ( $3 \mu \mathrm{g}$; D-19; Santa Cruz Biotechnology) or goat control IgG ( $3 \mu \mathrm{g}$; Sigma) for $24 \mathrm{~h}$ at $4^{\circ} \mathrm{C}$, followed by incubation with $20 \mu \mathrm{l}$ of Protein G-Sepharose for 3-4h. The beads were washed three times and were then subjected to immunoblotting (Asada et al., 2007).

Primary antibodies used were rabbit anti-GFP antibody (1:1000; Invitrogen), rabbit anti-GSK3 $\beta$ antibody (H-76; 1:500; Santa Cruz Biotechnology), rabbit anti-Ser9-phosphorylated GSK3 $\beta$ antibody (1:1000; Cell Signaling Technology), mouse anti-LKB1 antibody (clone 5c10; 1:1000; Millipore), rabbit anti-MO25 antibody (1:1000; Cell Signaling Technology), and rabbit anti-STRAD antibody (1:100; Abcam).

In utero electroporation. In utero electroporation was performed as described previously (Sanada and Tsai, 2005). For knockdown of LKB1, the GFP-expressing plasmid ( $2 \mathrm{mg} / \mathrm{ml}$, pCAG-IRES-GFP) was coinjected with the RNAi construct $(5 \mathrm{mg} / \mathrm{ml})$. For analysis of roles of GSK3 $\beta$ S9A, either the plasmid expressing GFP $(2 \mathrm{mg} / \mathrm{ml}$, pCAGIRES-GFP plasmid) or the plasmid coexpressing GSK3 $\beta$ S9A and GFP ( $2 \mathrm{mg} / \mathrm{ml}$, pCAG-GSK3 $\beta$ S9A-IRES-GFP) was injected. To label the centrosome, DsRed2-CentrinII-expressing plasmid $(5 \mathrm{mg} / \mathrm{ml})$ were coinjected. For mutAPC-overexpression experiments, the plasmid encoding either full-length APC- or mutAPC $(3 \mathrm{mg} / \mathrm{ml})$ was coinjected with the GFP-expressing plasmid $(3 \mathrm{mg} / \mathrm{ml})$. After the plasmid injection into the lateral ventricle of the embryos, electric pulses (four $50 \mathrm{~ms}$ square pulses of $38 \mathrm{~V}$ with $950 \mathrm{~ms}$ intervals) were applied to the embryos once or twice.

Immunohistochemistry. For immunostaining with antibodies against Ser9-phosphorylated GSK3 $\beta$, total GSK3 $\beta$, and Pan-Cadherin, brains were dissected from E16 (for Pan-Cadherin staining) or E17 embryos (for Ser9-phosphorylated GSK3 $\beta$ and total GSK3 $\beta$ staining), and then fixed with a HEM solution ( $80 \mathrm{~mm}$ HEPES, $5 \mathrm{~mm}$ EGTA, and $1 \mathrm{~mm}$ $\mathrm{MgCl}_{2}$; $\mathrm{pH}$ 6.8) containing 3.7\% formalin for $30 \mathrm{~min}$ at room temperature. The fixed brains were cryoprotected with PBS containing 25\% sucrose overnight at $4^{\circ} \mathrm{C}$, and embedded in OCT compound (Sakura Tissue Tek). The brain sections ( $15 \mu \mathrm{m}$ thick for Ser9-phosphorylated GSK3 $\beta$ and total GSK $3 \beta$ staining, or $30 \mu \mathrm{m}$ thick for Pan-Cadherin staining) prepared with a cryostat were subjected to antigen-retrieval treatment with HistoVT One (Nacalai Tesque), blocked with PBS containing 5\% FBS, $3 \%$ BSA, and $0.2 \%$ Triton X-100, and then subjected to immunostaining as described previously (Sanada and Tsai, 2005).

For GFP staining, brains were fixed with $4 \%$ paraformaldehyde/PBS overnight at $4^{\circ} \mathrm{C}$. The brain sections $[150 \mu \mathrm{m}$ thick for supplemental Fig. S5 (available at www.jneurosci.org as supplemental material), $60 \mu \mathrm{m}$ thick for other figures] were prepared with a vibratome, blocked with PBS containing 5\% FBS, 3\% BSA, and $0.2 \%$ Triton X-100, and then subjected to immunostaining as described previously (Asada et al., 2007).

Primary antibodies used were rabbit anti-GSK3 $\beta$ antibody (H-76; 1:50; Santa Cruz Biotechnology), rabbit anti-Ser9-phosphorylated GSK3 $\beta$ antibody (1:25; Cell Signaling Technology), rabbit anti-GFP antibody (1:1000; Invitrogen), rat anti-GFP antibody (1:1000; Nacalai Tesque), and mouse anti-Pan-Cadherin antibody (clone CH-19; 1:100; Sigma).

Preparation of acute brain slices and time-lapse imaging. Acute brain slices were prepared as described previously (Sanada and Tsai, 2005) with slight modifications. Electroporated brains were dissected from E17 embryos in ice-cold dissection media [DMEM/F12 supplemented with D-glucose (final concentration $6.05 \mathrm{~g} / \mathrm{L}$ )] that was previously oxygenized and conditioned with $95 \% \mathrm{O}_{2} / 5 \% \mathrm{CO}_{2}$ for $20 \mathrm{~min}$ on ice. The brain slices (300 $\mu \mathrm{m}$ in thickness) were prepared with a vibratome in the ice-cold and preconditioned dissection media. The slices were then transferred onto $35 \mathrm{~mm}$ glass-bottom dishes (Matsunami Glass), and were overlaid with collagen (Cellmatrix IA, type I Collagen; Nitta Gelatin) for immobilization. The dishes were then placed in a humidified chamber $\left(5 \% \mathrm{CO}_{2} /\right.$ $95 \%$ air, $37^{\circ} \mathrm{C}$ ) for $10-20 \mathrm{~min}$ for gel solidification, and $1 \mathrm{ml}$ of prewarmed culture media (Neurobasal medium supplemented with B27, 5\% horse serum, and 5\% FBS) (Invitrogen) was added into the dish, followed by incubation for $3 \mathrm{~h}$ in a humidified chamber.

GFP-labeled cells were viewed under $5 \% \mathrm{CO}_{2} / 95 \%$ air at $37^{\circ} \mathrm{C}$ through a $40 \times$ oil-immersion objective (NA 1.0) of a Axio observer inverted microscope with a PM S1 incubator (Carl Zeiss Microimaging). Time- 
lapse images were collected with an AxioCam cooled CCD camera (Carl Zeiss Microimaging) every $20 \mathrm{~min}$ for $4-5 \mathrm{~h}$.

Lattice culture of neocortical neurons, immunocytochemistry, and time-lapse imaging. Neocortical cells were prepared from E14 mouse embryos as described previously (Asada et al., 2007). The prepared cortical neurons were transfected with various combinations of plasmids encoding GFP, GSK3 $\beta$ S9A, DsRed2CentrinII, full-length APC, mutAPC, control RNAi, and LKB1 RNAi by the Nucleofector device (Amaxa). Transfected neurons were then plated at $4 \times 10^{5}$ cells $/ \mathrm{cm}^{2}$ on poly-D-lysineand laminin-coated coverslips in Neurobasal medium supplemented with N2 supplements, B27 supplements, and 10\% horse serum (Invitrogen). After $3 \mathrm{~h}$ in culture, culture medium was changed to serum-free medium. At $1 \mathrm{~d}$ in vitro (DIV; the plating day is defined as 0 DIV), lattice cultures were induced by supplementation of $5 \mathrm{kDa}$ dextran sulfate (final concentration $10 \mu \mathrm{g} / \mathrm{ml}$, Wako) into culture medium, as described previously (Nichols et al., 2008). At 2 DIV the cultures were subjected to immunocytochemistry or time-lapse imaging.

For immunocytochemistry, lattice cultures were fixed with $4 \%$ paraformaldehyde/PBS for $30 \mathrm{~min}$ at $37^{\circ} \mathrm{C}$, and then permeabilized and quenched with PBS containing $0.1 \mathrm{M}$ glycine and $0.1 \%$ Triton X-100 for $30 \mathrm{~min}$. Cultures were then blocked with PBS containing 5\% FBS, $3 \%$ BSA, and $0.2 \%$ Triton X-100, and subjected to immunostaining as described previously (Asada et al., 2007). Primary antibodies used were rabbit anti-GSK3 $\beta$ antibody (H-76; 1:50; Santa Cruz Biotechnology), rabbit antiSer9-phosphorylated GSK $3 \beta$ antibody (1:25; Cell Signaling Technology), rabbit anti-GFP antibody (1:1000; Invitrogen), rat anti-GFP antibody (1:1000; Nacalai Tesque), rat antiNestin antibody (1:200; BD Transduction Laboratories), mouse anti- $\alpha$-tubulin antibody (clone B-5-1-2; 1:1000; Sigma), rabbit antiAPC antibody (C-20; 1:50; Santa Cruz Biotechnology), rabbit anti-Glu-tubulin antibody (1:200; Sigma), and mouse anti-EB1 antibody (1:200; BD Transduction Laboratories).

Time-lapse images were collected every 3 min for 30-60 min as described above.

\section{Results}

\section{Role of LKB1 in neuronal migration}

We have previously demonstrated that LKB1 regulates neuronal migration in the developing neocortex (Asada et al., 2007). To inspect the effect of LKB1 knockdown on the overall morphology of migrating neurons as well as the position of the centrosome, we electroporated E14 mouse embryonic cortices with a LKB1 RNAi construct (Asada et al., 2007) together with the GFP-expressing plasmid and DsRed-tagged CentrinII (a marker of centrosome) plasmid (Tanaka et al., 2004). Consistent with our previous reports, knockdown of LKB1 severely retarded neuronal migration in vivo (Fig. $1 A$ ). Intriguingly, LKB1impaired migrating neurons displayed significantly longer lead-

$\mathrm{D}$

E
A

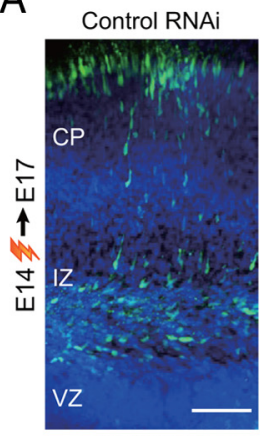

DAPI/GFP

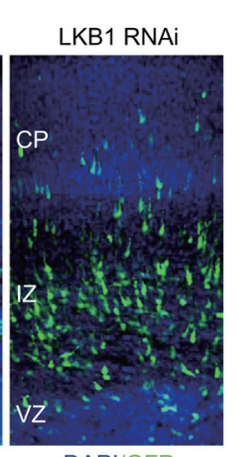

DAPI/GFP

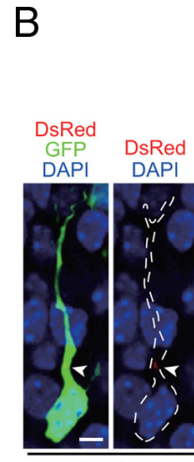

Control

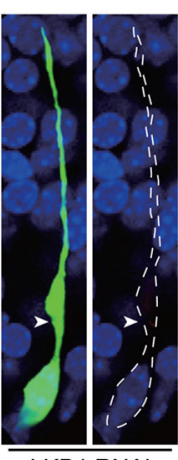

LKB1 RNAi
C

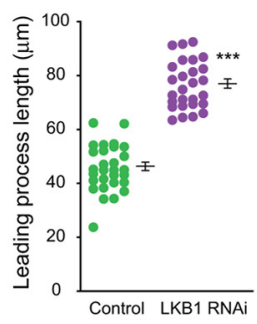

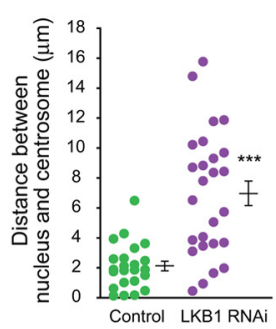
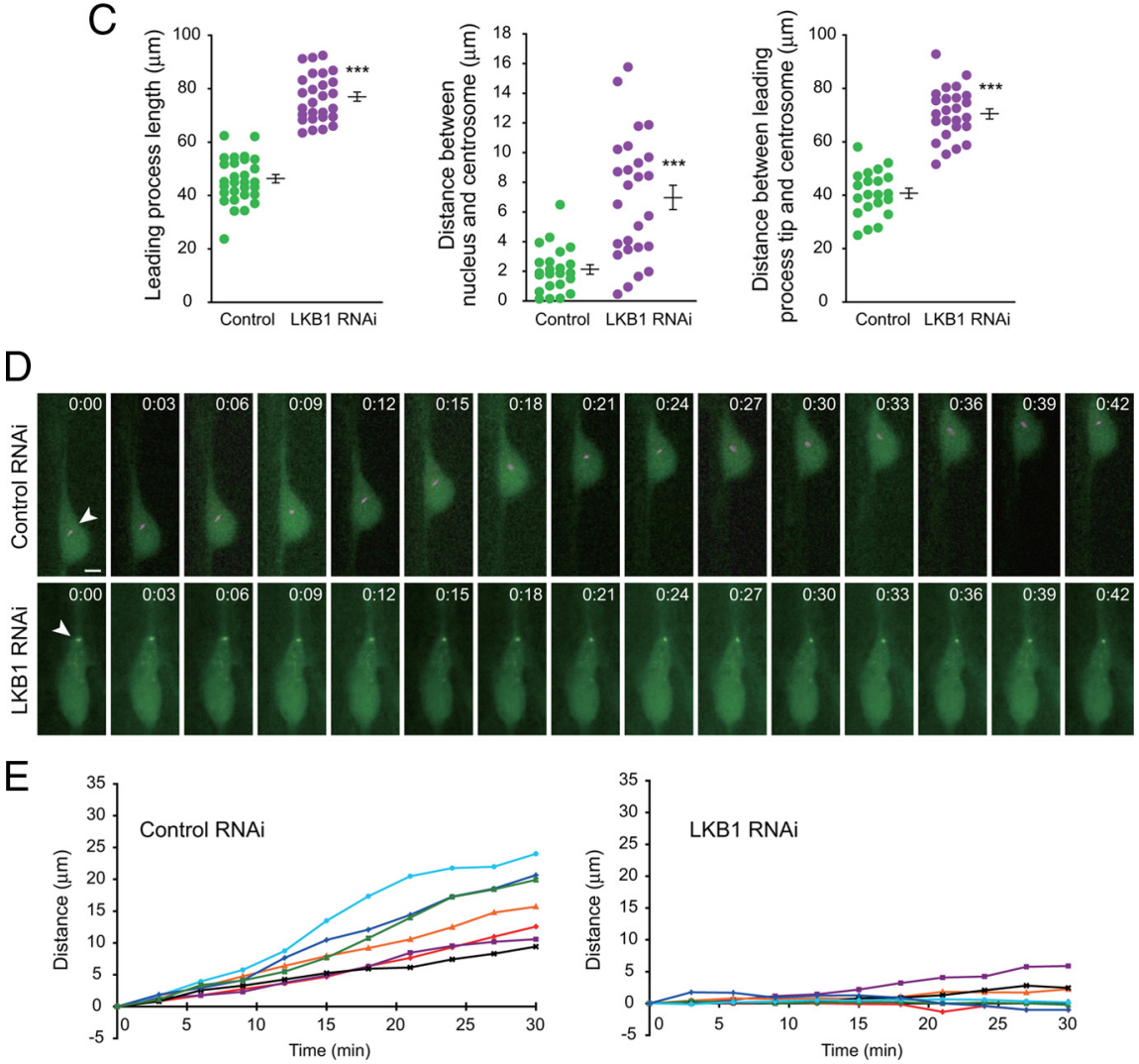

Figure 1. Effect of LKB1 knockdown on migrating neurons. $A, B$, Either control RNAi or LKB1 RNAi plasmid was electroporated into E14 mouse embryonic cortices together with plasmids encoding GFP and DsRed2-Centrinll. Brains were fixed at E17, and brain sections were immunostained with anti-GFP antibody. Nuclei were stained with DAPI. High-magnification images of the representative GFP-labeled migrating neurons in the upper IZ are shown in $\boldsymbol{B}$. Arrowheads indicate the position of the centrosome labeled by DsRed2-Centrinll. GFP-labeled cells are outlined with dashed lines. Scale bars: $100 \mu \mathrm{m}(\boldsymbol{A}), 5 \mu \mathrm{m}(\boldsymbol{B})$. C, The leading process length, the nucleus - centrosome distance, and the leading process tip-centrosome distance of GFP-positive migrating neurons in the upper IZ and lower (P were measured and plotted as the mean \pm SEM [leading process length: $n=29$ cells from 4 embryos (control) and 27 cells from 4 embryos (RNAi); nucleus- centrosome distance: $n=23$ cells from 4 embryos (control) and 26 cells from 4 embryos (RNAi); leading process tip-centrosome distance: $n=21$ cells from 4 embryos (control) and 25 cells from 4 embryos (RNAi)]. ${ }^{* * *} p<0.001$ versus control by two-tailed Welch's $t$ test. $\boldsymbol{D}$, Either control RNAi or LKB1 RNAi plasmid was transfected into neocortical neurons derived from E14 mouse embryos, together with the plasmids encoding GFP and DsRed2Centrinll. Transfected neurons were then subjected to lattice cultures. At 2 DIV, neurons apposed to fiber fascicles in lattice cultures were monitored by using 3 min time-lapse intervals. Time is denoted as hours:minutes in the top of each panel. The position of the centrosome is indicated by an arrow in the panels of time $=0: 00$. Scale bar, $5 \mu \mathrm{m}$. $\boldsymbol{E}$, The graphs show the representative centrosomal tracings in control cells (left) and LKB1-knockdown cells (right). ing process (LKB1 RNAi: $76.4 \pm 1.7 \mu \mathrm{m}$; control: $45.6 \pm 1.6 \mu \mathrm{m}$ ) and distance between centrosome and leading process tip (LKB1 RNAi: $70.4 \pm 2.0 \mu \mathrm{m}$; control: $40.6 \pm 1.9 \mu \mathrm{m}$ ) (Fig. $1 B, C$ ). In addition, the LKB1-knockdown neurons had the centrosome positioned far away from the nucleus $(6.9 \pm 0.8 \mu \mathrm{m})$ as compared to 
control neurons $(2.1 \pm 0.3 \mu \mathrm{m})$ (Fig. $1 B, C)$. Furthermore, when LKB1 mutant, which contains two silent mutations within the RNAi target sequence, was coexpressed, the defects of LKB1 RNAi-induced neurons were almost completely reversed in terms of neuronal positioning, leading process length, distance between nucleus and centrosome, and distance between leading process tip and centrosome (supplemental Fig. S1, available at www.jneurosci.org as supplemental material) (Asada et al., 2007). These results suggest that LKB1 contributes to multiple aspects of neuronal migration in the developing neocortex.

To further define the role for LKB1 in neuronal migration, we used lattice cultures of neocortical cells (Nichols et al., 2008) (see Materials and Methods). In this culture system, the aggregation of cells is interconnected by a lattice of fiber fascicles. Most of neurons that apposed to the fiber fascicles are known to exhibit the morphology and gene expression characteristic of in vivo radially migrating pyramidal neurons (Nichols et al., 2008) (supplemental Fig. S2, available at www.jneurosci.org as supplemental material). Importantly, the fiber-apposed neurons migrate along the fibers in a fashion similar to radial migration of neurons in brain slices (Nichols et al., 2008). We then transfected cortical cells with GFP and DsRed-CentrinII and subjected them to the lattice culture. When we imaged the cells that were apposed to the fiber fascicles and were sufficiently away from the cell aggregate formed the lattice, $>90 \%$ of the fiber-apposed neurons exhibited unidirectional migration. The centrosome in fiber-apposed neurons moved forward with a relatively continuous motion, and in most cases, the cell soma showed a saltatory movement (see Fig. $5 A$; supplemental Movie 1, available at www.jneurosci.org as supplemental material). In some cases, the centrosome and the cell soma moved with a relatively continuous motion (data not shown). The observed subcellular behaviors are reminiscent of those from radially migrating neurons in brain slices (Tsai et al., 2007; Nichols et al., 2008). When cortical neurons were transfected with the LKB1 RNAi construct together with the plasmids encoding GFP and DsRed-tagged CentrinII and were then subjected to the lattice culture, LKB1-impaired and fiber-apposed neurons possessed abnormally long leading process (see Figs. 2 E, $6 C, D)$. Time-lapse imaging of these neurons showed that the centrosome in LKB1-knockdown neurons was restricted at the base of the leading process and did not exhibit normal forward movement (Fig. 1D,E; supplemental Movie 2, available at www. jneurosci.org as supplemental material). On the other hand, control shRNA-introduced neurons exhibited directional and continuous movement of the centrosome (Fig. $1 D, E$ ), suggesting that LKB1 contributes to the centrosomal forward movement in migrating neurons.

\section{LKB1 mediates Ser9 phosphorylation of GSK3 $\beta$ in migrating neurons}

One candidate for the downstream effectors of LKB1 is the glycogen synthase kinase $3 \beta$ (GSK $3 \beta$ ). We have previously demonstrated that in primary differentiating neurons, Ser9 phosphorylation (inactivation) of GSK $3 \beta$ at the axon tip is mediated by LKB1 (Asada et al., 2007). To examine the possibility that LKB1 regulates Ser9 phosphorylation of GSK $3 \beta$ in migrating neurons, we first assessed the distribution of Ser9phosphorylated GSK $3 \beta$ and total GSK3 $\beta$ in the developing neocortex. Immunohistochemical analysis demonstrated that both total GSK3 $\beta$ and Ser9-phosphorylated GSK3 $\beta$ were enriched in the cortical plate $(\mathrm{CP})$ as well as in the intermediate zone (IZ) where migrating neurons are abundant (Fig. 2A). Detailed confocal microscopic analysis of migrating neurons showed that Ser9-phosphorylated GSK3 $\beta$ was distributed in the leading process (Fig. $2 \mathrm{~B}$ ). To further define the subcellular localization of Ser9-phosphorylated GSK3 $\beta$ in migrating neurons, we performed immunocytochemistry of fiber-apposed neurons in the lattice culture. As shown in Figure 2C, Ser9phosphorylated GSK $3 \beta$ was localized in the leading process, whereas total GSK $3 \beta$ is uniformly distributed throughout the cell soma and leading process (Fig. $2 C$ ). To inspect the detailed distribution of total GSK3 $\beta$ and its Ser9-phosphorylated form, we measured the fluorescence intensities of Ser9phosphorylated GSK $3 \beta$, total GSK $3 \beta$, and GFP in the leading process. Similar to the distribution pattern of GFP, the fluorescence intensity of total GSK $3 \beta$ in the leading process tip was less than that in the shaft (Fig. $2 C$ ), and the total GSK3 $\beta$ / GFP ratio in the tip and shaft was similar to each other (Fig. $2 D)$. On the other hand, Ser9-phosphorylated GSK3 $\beta$ was relatively evenly distributed in the tip and shaft (Fig. $2 C$ ), and the Ser9-phosphorylated GSK3 $\beta /$ GFP ratio in the tip was significantly higher than that in the shaft (Fig. 2D). Thus, there is an increased Ser9-phosphorylated/inactivated fraction of total GSK $3 \beta$ in the leading process tip of migrating neurons. These observations indicate a reduction in total amount of active GSK3 $\beta$ in the tip when compared to the shaft, and underscore the localized inactivation of GSK $3 \beta$ at the leading process tip of migrating neurons.

We then investigated the potential involvement of LKB1 in the Ser9 phosphorylation of GSK $3 \beta$. To test this, neocortical neurons were transfected with the GFP- and LKB1 shRNA-expressing plasmids, subjected to lattice cultures, and immunostained with anti-Ser9-phosphorylated GSK3 $\beta$ antibody at 2 DIV. In control neurons, Ser9-phosphorylated GSK3 $\beta$ was distributed in the leading process of migratory neurons (Fig. $2 E$ ). On the other hand, in LKB1 shRNA-introduced cultures, the immunoreactivity in the leading process of GFP-labeled migratory neurons was substantially diminished as compared to that of GFP-negative neurons on the same coverslip (Fig. 2E,F). We then examined the relevance of this phenotype in vivo. For this purpose, we electroporated the LKB1 shRNA- and GFP-expressing plasmids into E14 mouse embryonic cortices and analyzed the immunoreactivity for Ser9-phosphorylated GSK3 $\beta$ in the GFP-positive, LKB1-impaired migrating neurons in the IZ at E17. LKB1knockdown neurons possessed abnormally long leading process (Fig. $2 G$, see also Fig. $1 B$ ). We then measured the immunofluorescence intensity of Ser9-phosphorylated GSK3 $\beta$ in the leading process of GFP-labeled neurons and that in the neighboring region where GFP-negative neurons reside. For control neurons, the mean value of the fluorescence intensity in the leading process was about twice as high as that in the neighboring region (process region/ neighboring region: $1.939 \pm 0.101, n=30$ neurons). In contrast, intensity values in the process and the neighboring region were similar in the case of LKB1-knockdown neurons ( $1.108 \pm 0.034, n=30$ neurons; $p<0.001$ by two-tailed Welch's $t$ test), suggesting a marked reduction of the fluorescence signals of Ser9-phosphorylated GSK3 $\beta$ in the leading process. Together, these results suggest that LKB1 mediates the Ser9 phosphorylation of GSK $3 \beta$ in the leading process of in vivo migrating neurons. In addition, to examine the in vivo interaction between GSK $3 \beta$ and LKB1, we performed a coimmunoprecipitation assay using mouse forebrain lysates prepared at E16 when radial migration is most active. GSK $3 \beta$ coimmunoprecipitated with LKB1 using LKB1 antibodies (Fig. $2 H$ ), supporting the idea that GSK3 $\beta$ is an in vivo target and effector of LKB1. 
A

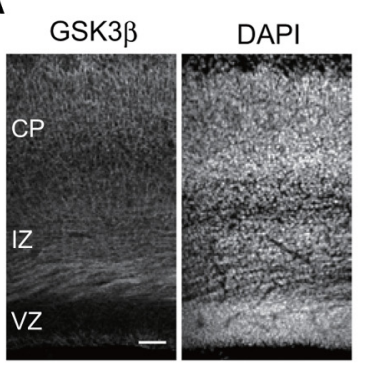

pGSK3 $\beta$

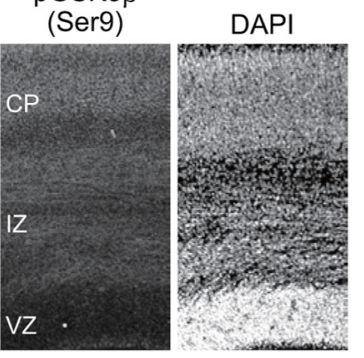

B

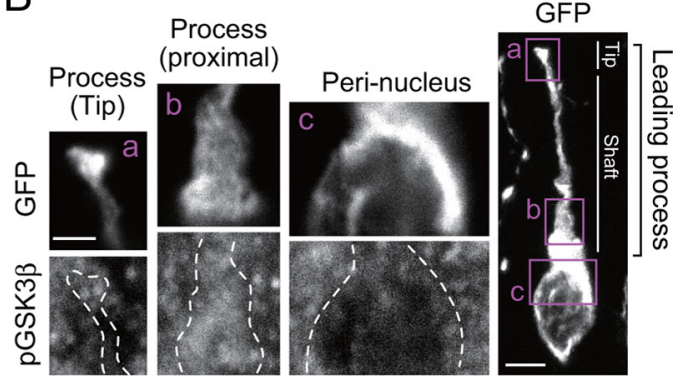

\section{C}
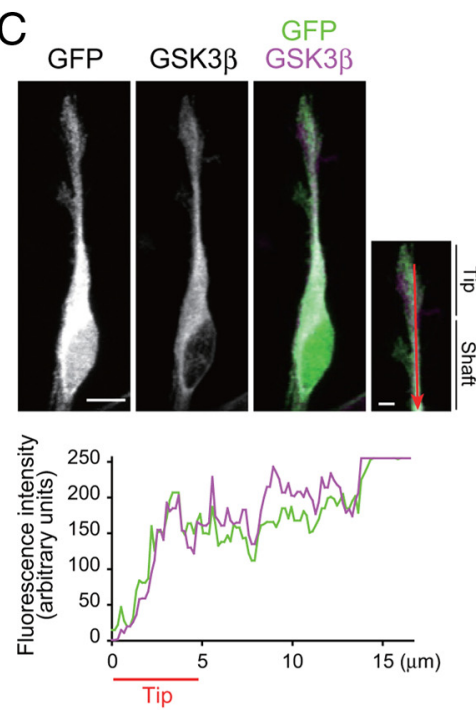

GFP

pGSK3 $\beta$ pGSK3
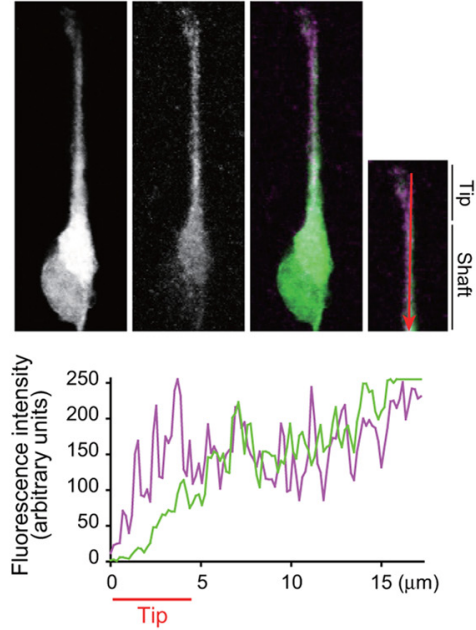

E
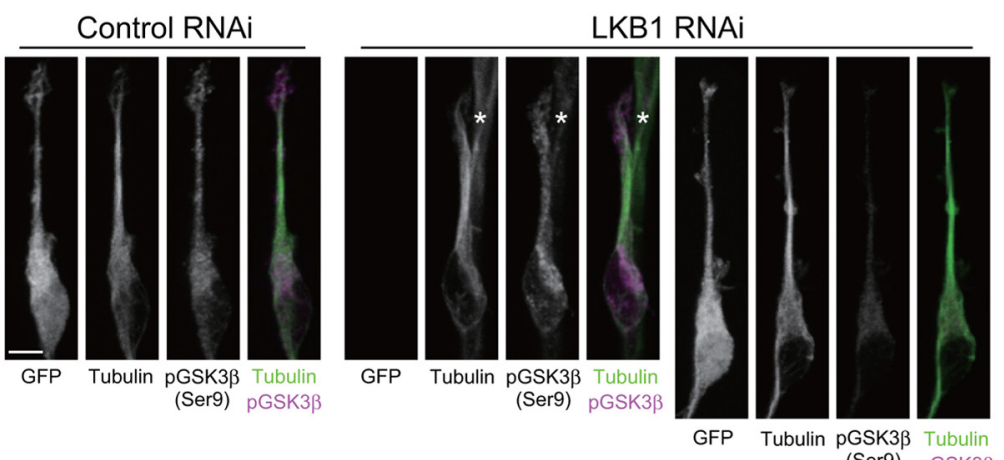

G
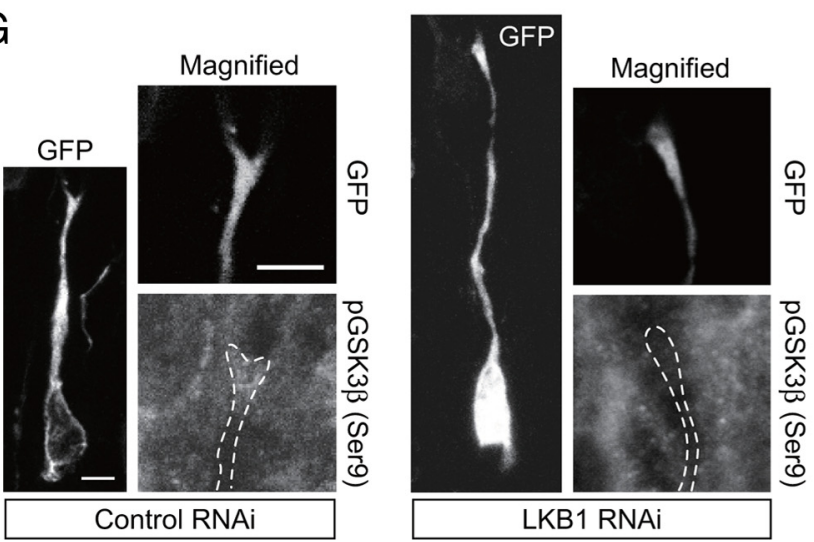

D

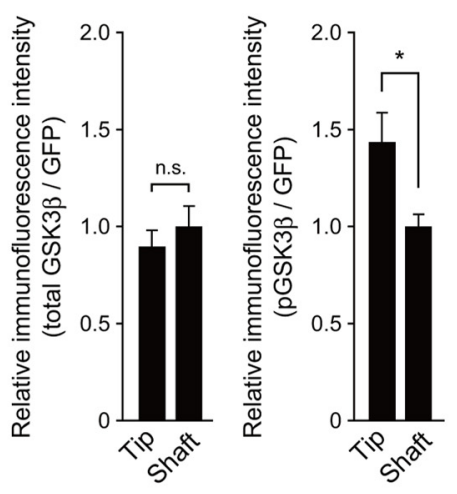

F

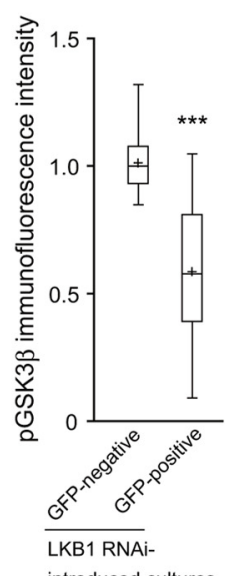

introduced cultures

$\mathrm{H}$

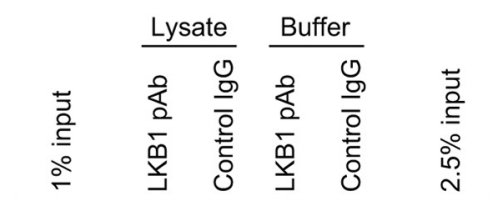

GSK3 $\beta$

LKB1

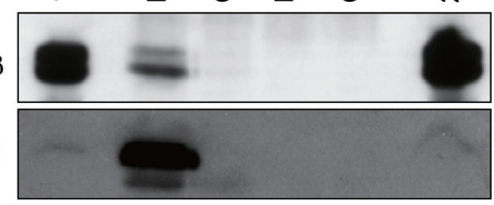

Figure 2. LKB1 mediates Ser9 phosphorylation of GSK3 $\beta$ in the leading process of migrating neurons. $A$, Coronal brain cryosections from E17 mouse embryos were immunostained with either anti-GSK3 $\beta$ antibody or anti-Ser9-phosphorylated GSK3 $\beta$ antibody. Nuclei were stained with DAPI. Scale bar, $50 \mu \mathrm{m}$. VZ, Ventricular zone. IZ, Intermediate zone. CP, Cortical plate. B, GFPexpressing plasmid was electroporated into E14 mouse embryonic cortices, and the brains were fixed at E17. The brain sections were immunostained with antibodies against GFP and Ser9phosphorylated GSK3 $\beta$. The representative confocal images of a GFP-positive migrating neuron in the upper IZ are shown. Left six panels (a-c) are high-magnification images (single $z$-sections) of the boxed regions in the right panel. The GFP-labeled neuron is outlined with dashed lines. Scale bars: $2 \mu \mathrm{m}$ (left), $5 \mu \mathrm{m}$ (right). The signals for Ser9-phosphorylated GSK3 $\beta$ were clearly detected in the process $(\boldsymbol{a}, \boldsymbol{b})$, but less in the nucleus $(\boldsymbol{c})$. C, Neocortical cells from E14 mouse embryos were transfected with the GFP-expressing plasmid, and then (Figure legend continues.) 
A

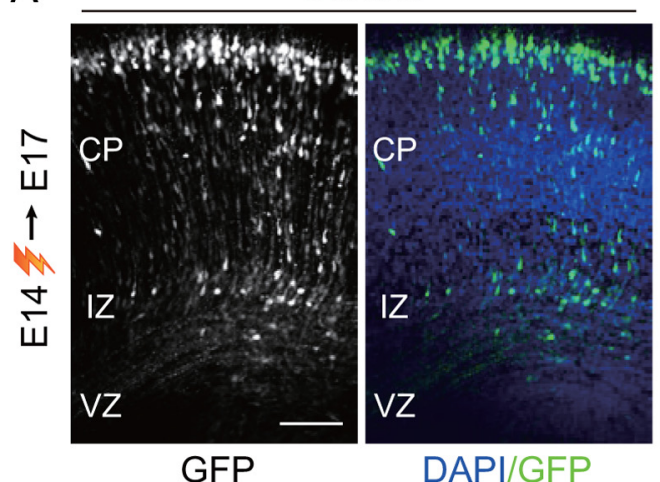

$\mathrm{B}$

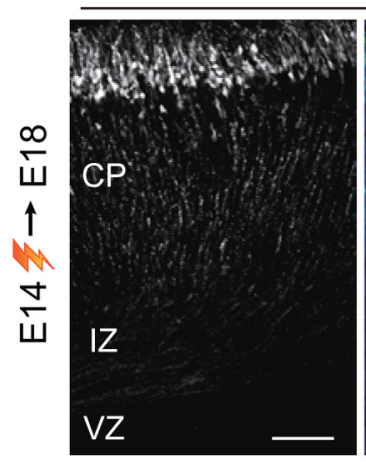

GFP
Control

Control

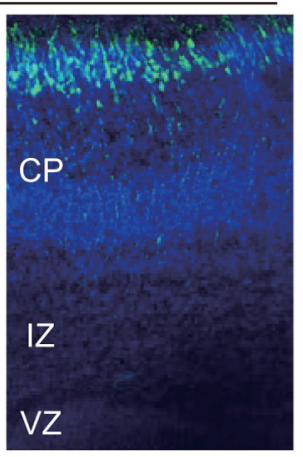

DAPI/GFP

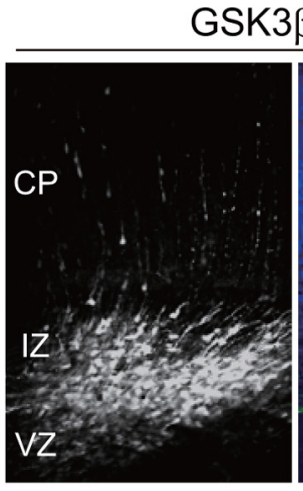

GFP

\section{S S9A}

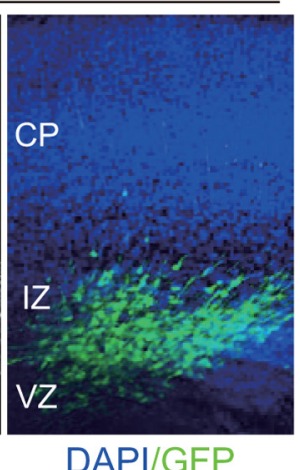

DAPI/GFP
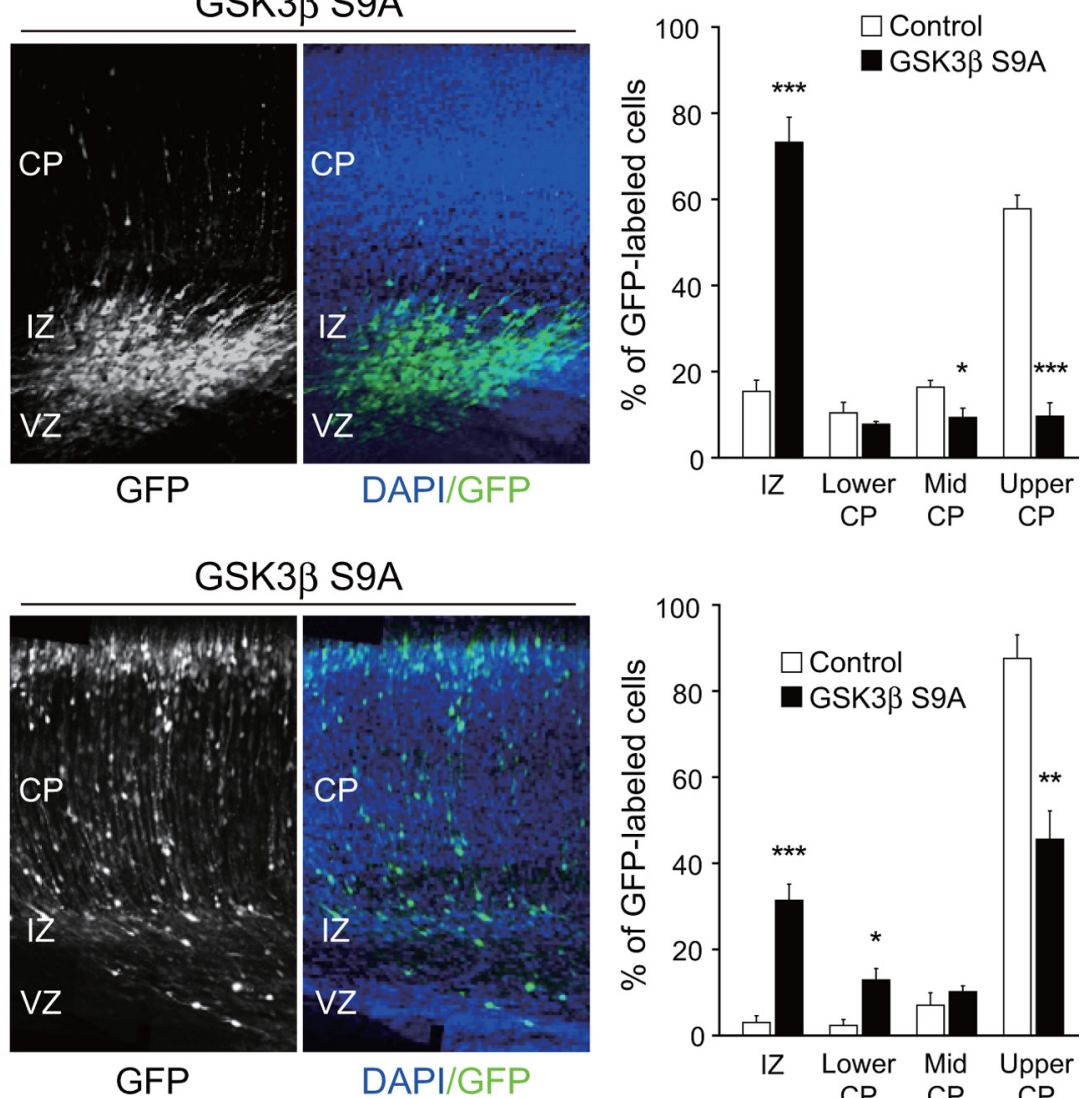

Figure 3. Ser9 phosphorylation of GSK3 $\beta$ is required for neuronal migration in vivo. $\boldsymbol{A}, \boldsymbol{B}$, Either the control plasmid (pCAG-IRES-GFP) or GSK3 $\beta$ S9A-expressing plasmid (pCAG-GSK3 $\beta$ S9A-IRES-GFP) was electroporated into E14 embryos, and brains were fixed at E17 $(\boldsymbol{A})$ and E18 (B). Brain sections were immunostained with anti-GFP antibody. Nuclei were stained with DAPI. The percentage of GFP-labeled cells in the IZ and CP of the E17 $(\boldsymbol{A})$ and E18 $(\boldsymbol{B})$ brain sections was calculated and plotted as the mean \pm SEM $[n=5$ embryos (total 560 neurons analyzed) for control at E17, and 6 embryos (total 1268 neurons analyzed) for GSK3 $\beta$ S9A at E17; $n=4$ embryos (total 579 neurons analyzed) for control at E18, and 5 embryos (total 989 neurons analyzed) for GSK3 $\beta$ S9A at E18]. ${ }^{*} p<0.05,{ }^{* *} p<0.01,{ }^{* * *} p<0.001$ versus control by two-tailed Welch's $t$ test. Scale bars, $100 \mu \mathrm{m}(\boldsymbol{A}, \boldsymbol{B})$.

\section{Ser9 phosphorylation of GSK3 $\beta$ is important for neuronal migration}

Since LKB1 mediates inactivation of GSK3 $\beta$ through Ser9 phosphorylation, GSK3 $\beta$ likely contributes to neuronal migration. However, to date, no clear evidence of an involvement of GSK3 $\beta$ in neuronal migration has been provided. Hence, we determined a potential role for Ser9 phosphorylation of GSK3 $\beta$ in neuronal migration. For this, a plasmid (pCAG-GSK3 $\beta$ S9A-IRES-GFP) encoding GSK3 $\beta$ S9A mutant (Ser9 is replaced with alanine; Ser9 phosphorylation resistant and constitutively active kinase) was introduced into E14 mouse neocortices, and the distribution of GFP-labeled cells was analyzed at E17, E18, and P4 (postnatal day 4 ; the birth date is defined as P0). At E17, the majority of GSK3 $\beta$ S9A-expressing neurons $(73.3 \pm 5.8 \%)$ was distributed in the IZ, and a small population of neurons was found in the $\mathrm{CP}(26.7 \pm$ $5.9 \%$ ) (Fig. 3A). In marked contrast, most of control neurons have readily migrated into the $\mathrm{CP}(84.6 \pm 7.2 \%$ in the $\mathrm{CP} ; 15.4 \pm$ $2.6 \%$ in the IZ) at that time (Fig. $3 A$ ). At E18, a certain population

$\leftarrow$

(Figure legend continued.) subjected to lattice cultures. At 2 DIV, neurons in lattice cultures were fixed and immunostained with antibodies against GFP/total GSK3 $\beta$ (left panels) or GFP/Ser9phosphorylated GSK3 $\beta$ (right panels). Confocal images of neurons apposed to fiber fascicles are shown. The fluorescence intensities of GFP (green line) and total GSK3 $\beta$ (magenta line) along the red arrow are plotted in the left graph, and those of GFP (green line) and Ser9-phosphorylated GSK3 $\beta$ (magenta line) along the red arrow are plotted in the right graph. Scale bars: $5 \mu \mathrm{m}$ (large panels), $2 \mu \mathrm{m}$ (small panels). $\boldsymbol{D}$, The ratio of immunofluorescence intensities of total GSK3 $\beta$ to GFP in the tip and that in the shaft of individual cells is quantified. The relative values are plotted as the mean \pm SEM, with the mean value in the shaft set as 1.0 ( $n=30$ cells). Same quantification was performed for Ser9-phosphorylated GSK3 $\beta$ ( $n=30$ cells). ${ }^{*} p<0.05$ by tw0-tailed Welch's $t$ test. $n . s .$, Not significant, $p>0.4$ by two-tailed Welch's t test. $\boldsymbol{E}$, Either control RNAi or LKB1 RNAi plasmid was transfected into neocortical neurons derived from E14 mouse embry0s, together with GFP-expressing plasmid. Transfected neurons were then subjected to lattice cultures. At 2 DIV, neurons were fixed and immunostained with antibodies against GFP, tubulin, and Ser9-phosphorylated GSK3 $\beta$. Representative images of fiber-apposed neurons are shown (Scale bar, $5 \mu \mathrm{m}$ ). The fibers indicated by an asterisk are scaffold fibers. $\boldsymbol{F}$, The immunofluorescence intensities (per pixel in the cells) of Ser9-phosphorylated GSK3 $\beta$ in GFP-labeled and GFP-negative apposed neurons in LKB1 shRNA-introduced cultures (on the same coverslip) were measured. Box-and-whisker plots indicate the mean (cross within the box), 25th percentile (bottom line of the box), median (middle line of the box), 75th percentile (top line of the box), and minimum and maximum measurements (whiskers). The relative values are shown in the graph, with the mean value in GFP-negative group set as 1.0 ( $n=18$ and 20 cells for GFP-negative and GFP-positive, respectively). ${ }^{* * *} p<0.001$ versus GFP-negative cells by two-tailed Welch's $t$ test. G, Either control RNAi or LKB1 RNAi plasmid was electroporated into E14 mouse embryonic cortices together with GFP-expressing plasmid, and brains were fixed at E17. The brain sections were immunostained with antibodies against GFP and Ser9-phosphorylated GSK3 $\beta$. The representative confocal images of GFP-positive migrating neurons in the upper IZ are shown. High-magnification images of the distal part of the leading process of the neurons are also shown. The GFP-labeled leading processes are outlined with dashed lines. Scale bars, $5 \mu \mathrm{m}$. $\boldsymbol{H}$, E16 forebrain lysates (lysate) and lysis buffer (buffer) were subjected to immunoprecipitation with an anti-LKB1 antibody (LKB1 pAb) or control IgG (control IgG). The immunoprecipitates were then immunoblotted with antibodies against GSK3 $\beta$ and LKB1. Input is $1 \%$ or $2.5 \%$ of the starting material. The two bands for GSK3 $\beta$ are due to alternative splicing. 
of GSK3 $\beta$ S9A-expressing neurons entered the CP $(68.6 \pm 10.6 \%)$ (Fig. $3 B$ ), and at $\mathrm{P} 4$, almost all of the neurons reside in the CP (supplemental Fig. S3, available at www.jneurosci.org as supplemental material). These results indicate that GSK3 $\beta$ S9A-introduced neurons show severe retardation of neuronal migration. In addition, wild-type GSK $3 \beta$ introduced neurons showed almost normal migration, indistinguishable from control neurons (supplemental Fig. S4, available at www.jneurosci.org as supplemental material). Thus, Ser9 phosphorylation of GSK $3 \beta$ is required for proper neuronal migration in vivo.

\section{Ser9 phosphorylation of GSK3 $\beta$ is required for centrosomal forward movement}

To examine as to how disruption of Ser9 phosphorylation of GSK3 $\beta$ affects neuronal migration, we electroporated E14 embryos with the DsRed-tagged CentrinII plasmid together with the GSK3 $\beta$ S9Aexpressing plasmid (pCAG-GSK3 $\beta$ S9AIRES-GFP). In the control brains at E17, GFP-positive neurons in the upper IZ extended $\sim 47-\mu \mathrm{m}$-long leading process $(46.6 \pm 1.7 \mu \mathrm{m})$ (Fig. $4 A$ ), and displayed centrosome positioned at the apical side of the nucleus $(1.9 \pm 0.3 \mu \mathrm{m}$ from nucleus; $43.9 \pm 2.0 \mu \mathrm{m}$ from leading process tip) (Fig. $4 B$ ). On the other hand, GSK3 $\beta$ S9A-expressing neurons within the upper IZ exhibited significantly longer processes $(91.1 \pm 4.2 \mu \mathrm{m})$ (Fig. $4 A$ ), and a markedly increased distance between centrosome and leading process tip (91.8 \pm 3.7 $\mu \mathrm{m})$ (Fig. $4 B$ ), similar to LKB1-knockdown neurons (Fig. $1 B, C$ ). In GSK3 $\beta$ S9A-expressing neurons, the centrosome was positioned at close proximity of the nucleus $(1.5 \pm 0.3 \mu \mathrm{m})$, with no statistically significant differences when compared the control neurons (Fig. 4B).

We then analyzed by time-lapse imaging the centrosomal movement of fiberguided migrating neurons transfected with the GSK $3 \beta$ S9A plasmid and DsRedtagged CentrinII plasmid. GSK3 $\beta$ S9Aexpressing and fiber-apposed neurons possessed abnormally long leading process (see Fig. $6 A, B$ ), consistent with the morphology of GSK3 $\beta$-S9A-introduced migrating neurons in vivo (Fig. $4 A$ ). The centrosome of GSK3 $\beta$ S9A-expressing neurons was restricted to the perinuclear area and slightly moved back and forth

[Fig. 5A; supplemental Movie 1 (available at www.jneurosci.org as supplemental material) for control, supplemental Movie $3 \mathrm{~A}$ (available at www.jneurosci.org as supplemental material) for GSK3 $\beta$ S9A], indicating that GSK3 $\beta$ S9A impairs the directional

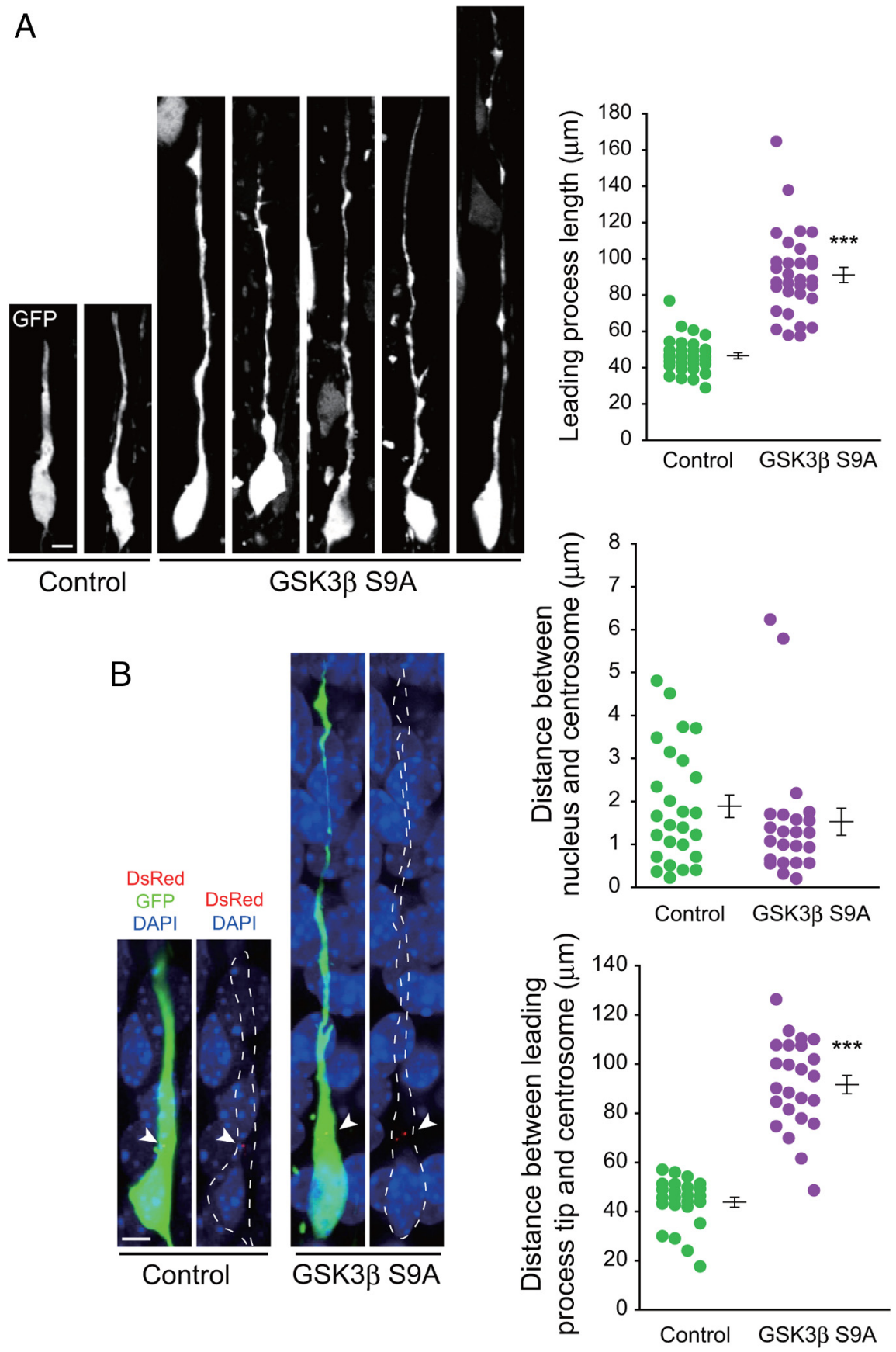

Figure 4. Introduction of GSK3 $\beta S 9 A$ increases the leading process length and the distance between centrosome and leading process tip. $\boldsymbol{A}, \boldsymbol{B}$, Either the control plasmid (pCAG-IRES-GFP) or the GSK3 $\beta$ S9A-expressing plasmid (pCAG-GSK3 $\beta$ S9A-IRES-GFP) was electroporated into $\mathrm{E} 14$ embryos together with the DsRed2-Centrinll-expressing plasmid. Brains were fixed at E17, and the brain sections were then immunostained with anti-GFP antibody. Nuclei were stained with DAPI. $\boldsymbol{A}$, The leading process length of GFP-positive migrating neurons in the upper IZ and lower CP was analyzed and plotted as the mean \pm SEM ( $n=32$ cells from 4 embryos, and 31 cells from 8 embryos for control and GSK3 $\beta$ S9A, respectively). Dots in the graph correspond to the leading process length for individual neurons. ${ }^{* * *} p<0.001$ versus control by two-tailed Welch's $t$ test. Scale bar, $5 \mu \mathrm{m}$. B, Arrowheads indicate the position of the centrosome labeled by DsRed2Centrinll. GFP-labeled cells are outlined with dashed lines. The distances between the nucleus and the centrosome, and between the leading process tip and the centrosome of GFP-positive migrating neurons in the upper IZ and lower CP were measured and plotted as the mean \pm SEM (nucleus-centrosome distance: $n=26$ cells from 4 embryos, and 23 cells from 8 embryos for control and GSK3 $\beta$ S9A, respectively; leading process tip - centrosome distance: $n=24$ cells from 4 embryos, and 24 cells from 8 embryos for control and GSK3 $\beta$ $S 9 A$, respectively). ${ }^{* * *} p<0.001$ versus control by two-tailed Welch's $t$ test. Scale bar, $5 \mu \mathrm{m}$.

centrosomal movement toward the leading process tip. To further confirm this result, we inspected centrosomal movement in migrating neurons in living brain slices. For this experiment, either the control or GSK3 $\beta$ S9A plasmid was electroporated with 

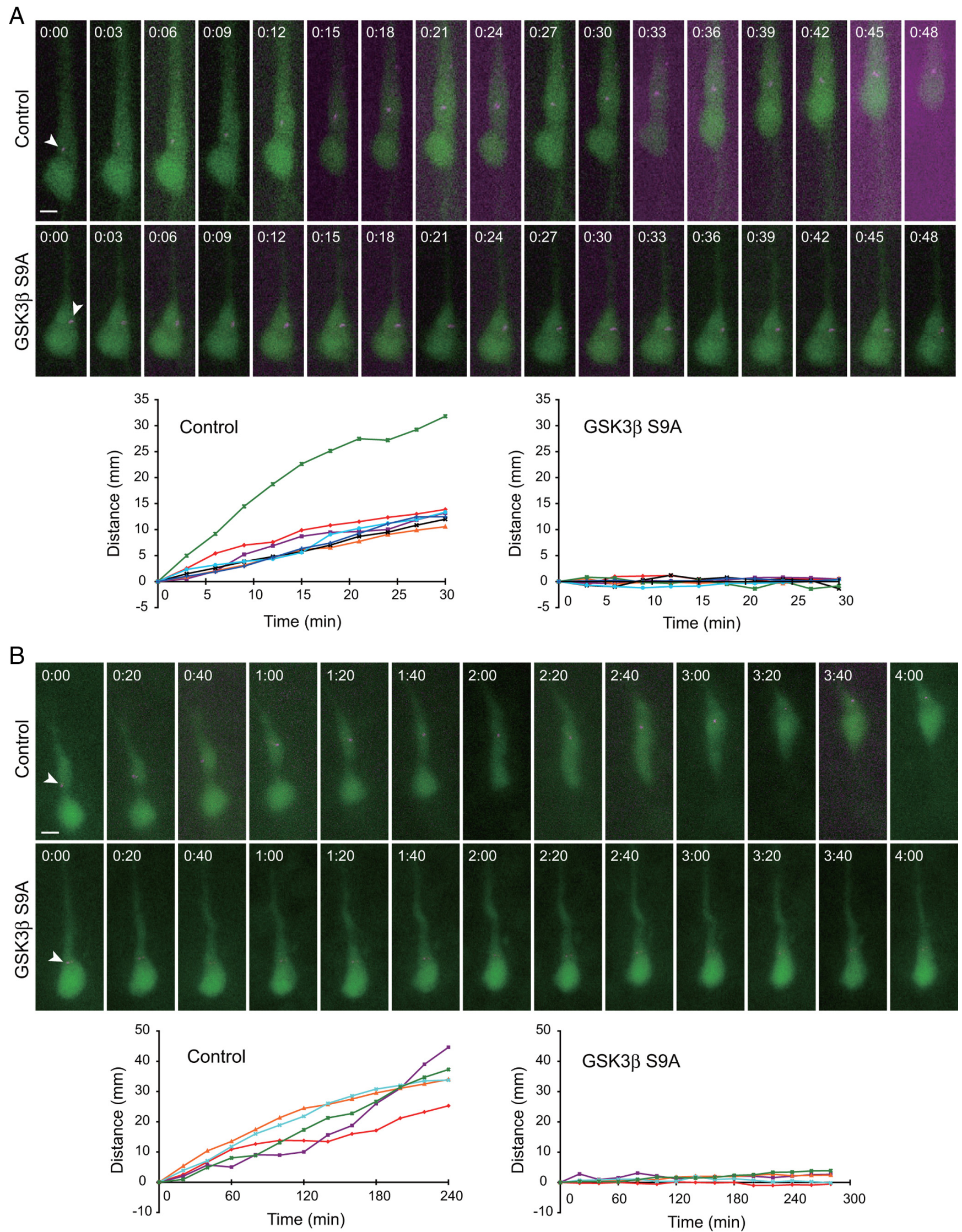

Figure 5. Ser9 phosphorylation of GSK3 $\beta$ is required for centrosomal forward movement. $\boldsymbol{A}$, Either the control plasmid (pCAG-IRES-GFP) or GSK3 $\beta$ S9A-expressing plasmid (pCAG-GSK3 $\beta$ S9A-IRES-GFP) was transfected into neocortical neurons from E14 mouse embryos together with the DsRed2-Centrinll-expressing plasmid. Transfected neurons were then subjected to lattice cultures. At 2 DIV, time-lapse imagings of neurons that are apposed to fiber fascicles were performed at 3 min intervals. Time is denoted as hours:minutes in the top of the each panel. The position of the centrosome is indicated by an arrow in the panels of time $=0: 00$. The graphs indicate the representative tracings of the centrosomal movement in (Figure legend continues.) 
the DsRed-tagged CentrinII plasmid into the E14 mouse neocortices, and the coronal slices prepared at E17 were subjected to time-lapse imaging. Control neurons within the IZ radially migrated in a typical saltatory manner, with unidirectional and continuous movement of the centrosome (Fig. $5 B$ ). In contrast, GSK3 $\beta$ S9A-expressing neurons showed severe retardation of centrosomal movement and neuronal migration during $4 \mathrm{~h}$ observations (Fig. 5B; supplemental Movie 3B, available at www. jneurosci.org as supplemental material). Together, these observations indicate that Ser9 phosphorylation of GSK3 $\beta$, just like LKB1, is required for centrosomal forward movement in migrating neurons.

\section{Both LKB1 and Ser9 phosphorylation of GSK3 $\beta$ are required for proper APC localization and microtubule stabilization at the leading process tip}

APC is a microtubule plus-end binding protein and one of the known substrates of GSK3 $\beta$ (Rubinfeld et al., 1996; MimoriKiyosue et al., 2000; Bienz, 2002; Etienne-Manneville and Hall, 2003). In migratory neurons in lattice culture, APC protein was distributed at the distal part of the leading process (Fig. 6A). More precisely, it was most frequently detected at the very end of microtubules $(67.7 \%, 134$ of 198 plus-ends of microtubules in 30 neurons) (Fig. 6A), suggesting that APC binds to the plus-ends of microtubules in the leading process tip. We then asked whether GSK $3 \beta$ activity is important for APC localization. In lattice cultures of neurons expressing GSK $3 \beta$ S9A, APC was abnormally distributed in the proximal leading process and cell soma, and rarely detected at the microtubule plus-ends in the leading process tip $(24.9 \%, 47$ of 189 plus-ends of microtubules in 30 neurons; $p<0.001$ by $\chi^{2}$ test) (Fig. $6 A$ ). In addition, GSK3 $\beta$ S9A-expressing neurons contained very low levels of Glu-tubulin (detyrosinated tubulin, a marker for stabilized microtubules) (Gundersen et al., 1984; Westermann and Weber, 2003) in the leading process tip when compared to control neurons with higher levels of Glu-tubulin-positive microtubules in the tip as well as in the process shaft (fluorescence intensity/pixel: GSK3 $\beta$ S9A, $11.1 \pm 1.5$ a.u., $n=30$ neurons; control, $25.8 \pm 3.2$ a.u., $n=$ 30 neurons; $p<0.001$ by two-tailed Welch's $t$ test). Similarly to GSK3 $\beta$ S9A-expressing neurons, LKB1-impaired neurons showed delocalization of APC from the microtubule plus-ends in the leading process tip $(24.6 \%, 46$ of 187 plus-ends of microtubules in 30 neurons; $p<0.001$ vs control neurons by $\chi^{2}$ test) (Fig. $6 C$ ), and loss of microtubule stabilization in the region (Glutubulin fluorescence intensity/pixel: $13.6 \pm 1.5$ a.u., $n=30$ neurons; $p<0.01$ vs control neurons by two-tailed Welch's $t$ test) (Fig. 6D). Altogether, these observations suggest that LKB1 and Ser9 phosphorylation of GSK3 $\beta$ influences APC localization and microtubule stabilization at the leading process tip of migrating neurons.

\section{$\leftarrow$}

(Figure legend continued.) control cells (left) and GSK3 $\beta$ S9A-expressing cells (right). Scale bar, $5 \mu \mathrm{m} . \boldsymbol{B}$, Either the control plasmid or GSK3 $\beta$ S9A-expressing plasmid was electroporated into E14 embryonic cortices together with the DsRed2-Centrinll-expressing plasmid. At E17, coronal slices were prepared and subjected to time-lapse imaging with $20 \mathrm{~min}$ intervals over a period of $4 \mathrm{~h}$. Time is denoted as hours:minutes in the top of each panel. The position of the centrosome is indicated by an arrow in the panels of time $=0: 00$. The graphs indicate the representative centrosomal tracings in control cells (left) and GSK3 $\beta$ S9A-expressing cells (right). Scale bar, $5 \mu \mathrm{m}$.

\section{Proper localization of APC to microtubules is necessary for microtubule stabilization in the leading process tip, centrosomal forward movement, and neuronal migration}

To explore a role for APC in neuronal migration, we used an APC construct lacking the C-terminal microtubule- and EB1-binding sites (mutAPC). The mutAPC is known to be transported normally to the distal part of microtubules (Mimori-Kiyosue et al., 2000; Zhou et al., 2004) via the N-terminal armadillo domain (Jimbo et al., 2002), but does not associate with individual microtubule plus-ends (Zhou et al., 2004). In addition, the mutAPC exerts a dominant-negative effect on APC's ability to associate with microtubules (Shi et al., 2004; Zhou et al., 2004), as it binds to the endogenous APC and interferes with its interaction to the microtubules. When mutAPC- and GFP-expressing plasmids were introduced into neurons in lattice culture, GFP-positive migratory neurons extended abnormally long leading process (Fig. 7A,B), just like LKB1-knockdown neurons and GSK3 $\beta$ S9A-introduced neurons. Importantly, immunostaining of mutAPC-expressing neurons with anti-APC antibody revealed that APC appears to be sequestered from the distal ends of microtubules, despite its existence in the leading process tip $38.6 \%$, 71 of 184 plus-ends of microtubules in 30 neurons; $p<0.001$ vs control neurons by $\chi^{2}$ test) (Fig. $7 A$, see also Fig. $6 A$ ). Consistently, the immunofluorescence intensity of APC at the very end of microtubules in mutAPC-expressing neurons were quite lower than that in control neurons (fluorescence intensity/pixel: mutAPC, $46.6 \pm 4.9$ a.u., $n=40$; Control, $60.0 \pm 3.6$ a.u., $n=40$, $p<0.05$ by two-tailed Welch's $t$ test). In addition, Glu-tubulin staining in the leading process tip was reduced (Glu-tubulin immunofluorescence intensity/pixel: $17.7 \pm 2.3$ a.u., $n=30$ neurons; $p<0.05$ vs control neurons by two-tailed Welch's $t$ test) (Fig. $7 B$, see also Fig. $6 B$ ), as observed in LKB1-impaired neurons and GSK3 $\beta$ S9A-transfected neurons. We then introduced the DsRed-tagged CentrinII plasmid and the GFP-expressing plasmid together with either the wild-type APC- (wtAPC-) or mutAPC-expressing plasmid into neurons, and the lattice cultures were subjected to time-lapse imaging at 2 DIV. The majority of wtAPC-expressing neurons showed directional and continuous centrosomal movement (Fig. 7C,D). In contrast, in mutAPCexpressing neurons, the centrosomal movement was severely impaired (Fig. 7C,D, supplemental Movie 4, available at www. jneurosci.org as supplemental material). Finally, we introduced the mutAPC-expressing and GFP-expressing plasmids into E14 mouse neocortices, and analyzed the morphology and distribution of GFP-positive cells at E17. Similarly to LKB1 shRNA- and GSK3 $\beta$ S9A-introduced neurons, mutAPC-transfected neurons possessed significantly longer leading processes (wtAPC, $53.7 \pm$ $1.9 \mu \mathrm{m}$; mutAPC, $71.6 \pm 2.5 \mu \mathrm{m}$ ) (Fig. $7 E$ ). Furthermore, a large number of wtAPC-transfected neurons migrated into the CP $(70.4 \pm 5.3 \%)$ at E17 (Fig. $7 F)$, while a significantly smaller population of mutAPC-expressing neurons were in the CP (49.8 \pm 4.3\%) (Fig. 7F). Thus, mutAPC-expressing neurons show phenotypes similar to those found in both LKB1-knockdown neurons and GSK3 $\beta$ S9A-introduced neurons. The neuronal migration defect observed in mutAPC-expressing neurons was unlikely attributed to the disruption of radial glial scaffold, as the mutAPC-expressing radial glial cells showed normal radial fibers reaching the pia, and normal apical localization of Cadherin (supplemental Fig. S5, available at www.jneurosci.org as supplemental material). Altogether, our results indicate that appropriate APC localization is required for the Glu-tubulin accumulation in the leading process tip, centrosomal forward movement, and neuronal migration. 
A

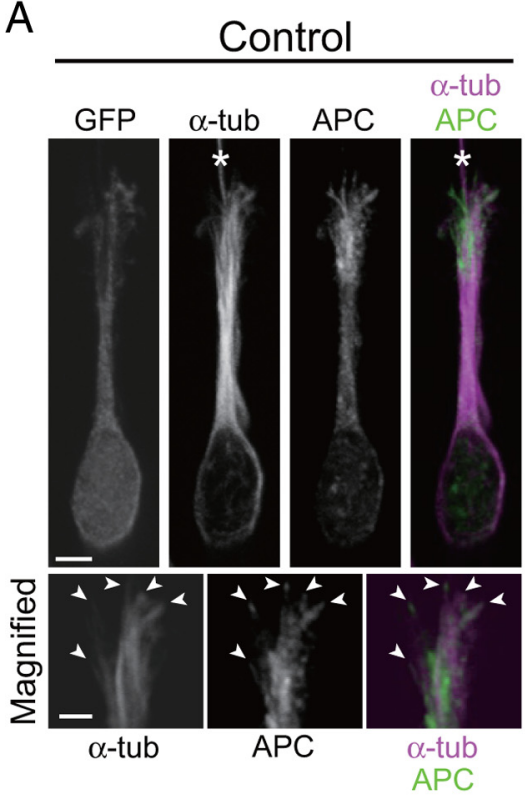

B

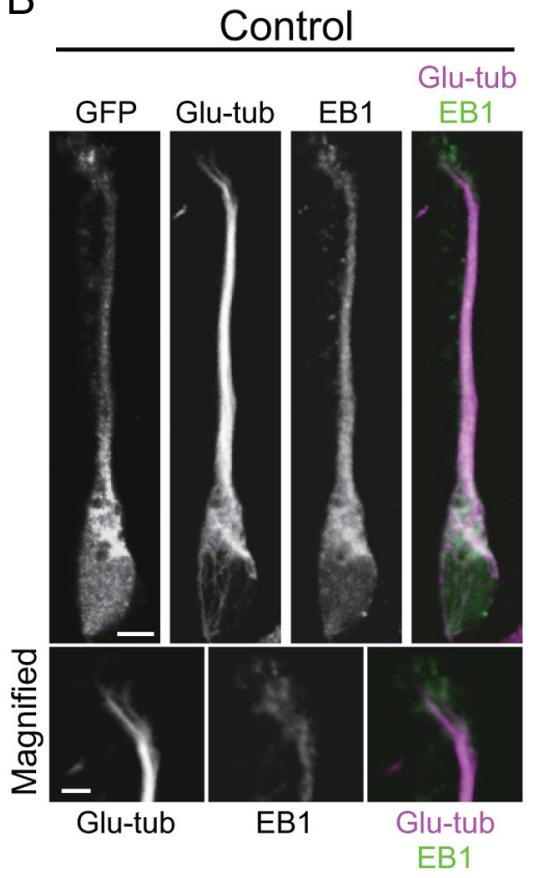

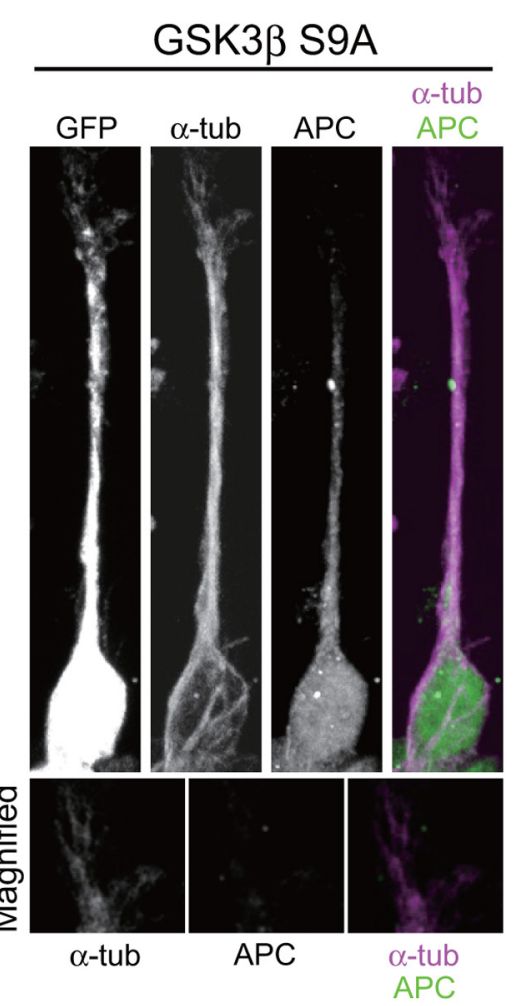

C
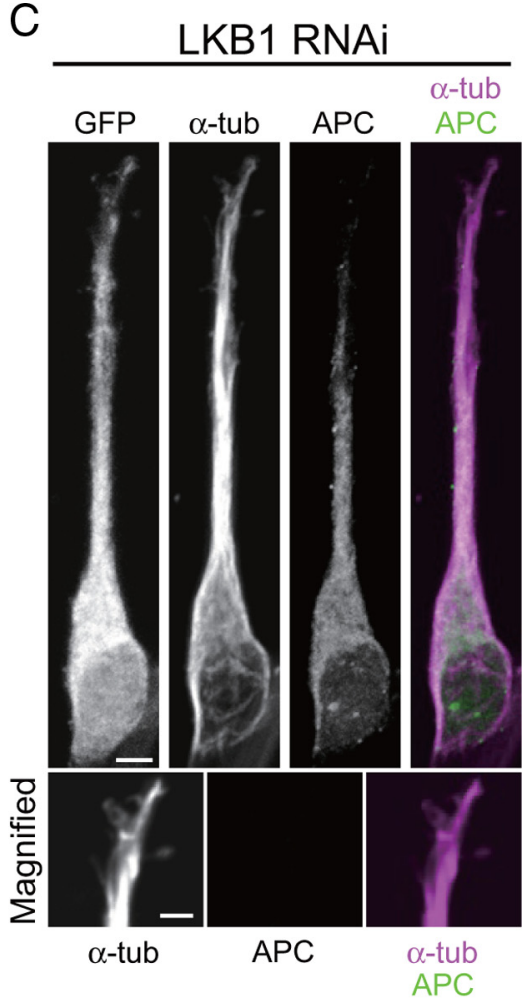

$\mathrm{D}$

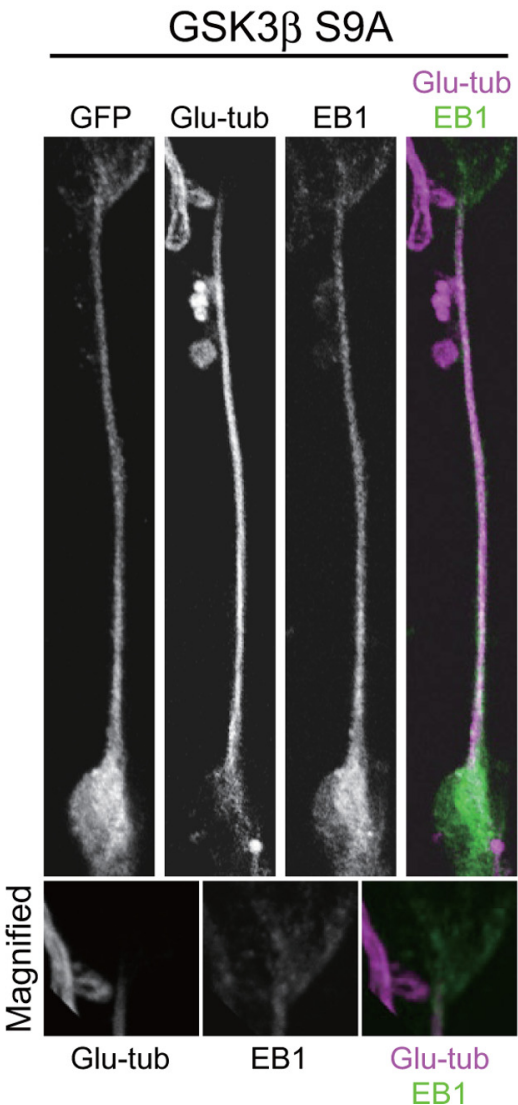

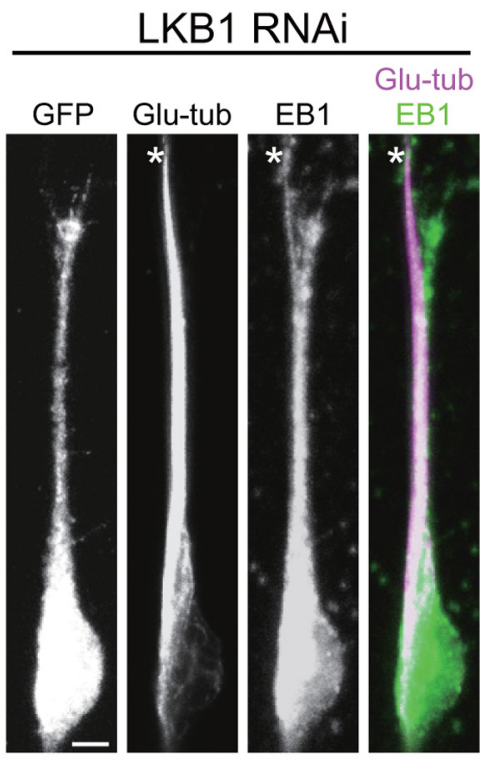

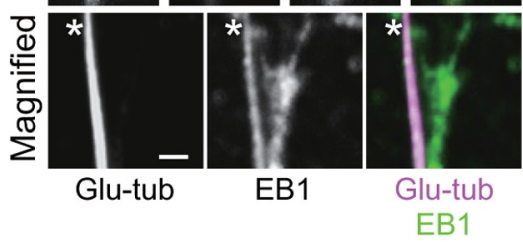

Figure 6. LKB1 and Ser9 phosphorylation of GSK3 $\beta$ are required for proper APC localization and microtubule stabilization at the leading process tip. A, Either the control plasmid (pCAG-IRES-GFP) or GSK3 $\beta$ S9A-expressing plasmid (PCAG-GSK3 $\beta$ S9A-IRES-GFP) was transfected into neocortical neurons derived from E14 mouse embryos. Transfected neurons were then subjected to lattice cultures. At 2 DIV, neurons that are apposed to fiber fascicles in the lattice cultures were fixed, and immunostained with antibodies against GFP, $\alpha$-tubulin, and APC. Small panels on the bottom are high-magnification images of the tip of the leading process of neurons in the upper panels (single focal plane images for control, and projection images for GSK3 $\beta$ S9A). The $\alpha$-tubulin-labeled fibers indicated by an asterisk in the control panel are scaffold fibers. APC is localized to the distal ends of the microtubules (indicated by arrowheads in control magnified panels). Scale bars: $2.5 \mu \mathrm{m}$ (upper panels), $2 \mu \mathrm{m}$ (bottom panels). B, Neurons transfected with control plasmid (pCAG-IRES-GFP) or GSK3 $\beta$ S9A-expressing plasmid (pCAG-GSK3 $\beta$ S9A-IRES-GFP) in the (Figure legend continues.) 


\section{Discussion}

In the present study, we demonstrate that Ser9-phosphorylated GSK $3 \beta$ is detected in the leading process of migrating neurons in the lattice culture as well as in the developing neocortex. Specifically, there is a reduced pool of active GSK3 $\beta$ in the leading process tip compared to the shaft, leading to the conclusion that GSK $3 \beta$ is highly inactivated in the leading process tip (Fig. $2 B-$ $D)$. Importantly, Ser9 phosphorylation of GSK3 $\beta$ is diminished by LKB1 knockdown (Fig. $2 E-G$ ), indicating that LKB1 controls Ser9 phosphorylation of GSK3 $\beta$ and spatially localizes the inactive kinase in migrating neurons. Of note, LKB1 interacts with GSK3 $\beta$ in the developing neocortex (Fig. $2 H$ ). Furthermore, when LKB1 and GSK3 $\beta$ was transiently transfected in HEK293T cells, GSK3 $\beta$ was coimmunoprecipitated with LKB1 (supplemental Fig. S6, available at www.jneurosci.org as supplemental material). Moreover, when LKB1 was immunoprecipitated from HEK cells transfected with either wild-type or kinase-dead LKB1 and subjected to in vitro kinase assays using recombinant GSK3 $\beta$ as a substrate, the Ser9 phosphorylation of GSK3 $\beta$ was significantly increased by wild-type LKB1, but not by kinase-dead mutant (D194A) (supplemental Fig. S7, available at www.jneurosci. org as supplemental material). Together, these observations support the idea that LKB1 directly associates with and phosphorylates GSK3 $\beta$ in the leading process. Alternatively, LKB1associated kinase(s) may relay LKB1 signaling to GSK3 $\beta$ phosphorylation. It has been reported that LKB1-dependent phosphorylation of members in AMPK-related kinases is enhanced by binding of STRAD and MO25 to LKB1 (Lizcano et al., 2004). We examined whether Ser9 phosphorylation of GSK3 $\beta$ and LKB1-GSK3 $\beta$ interaction is increased by STRAD and MO25. However, unlike AMPK-related kinases, phosphorylation of GSK $3 \beta$ and LKB1-GSK3 $\beta$ interaction were not enhanced (supplemental Figs. S6, S7, available at www.jneurosci.org as supplemental material), indicating that GSK3 $\beta$ is a LKB1 substrate whose Ser9 phosphorylation is hardly affected by LKB1's binding to STRAD and MO25. It is also known that LKB1 is spatially activated in the axon of primary hippocampal neurons through a process involving neurotrophic factor BDNF (Barnes et al., 2007; Shelly et al., 2007). Therefore, we speculate that extracellular cues released from the direction of migration induce a spatially restricted activation of LKB1 at the leading process tip, which would cause localized-inactivation of GSK $3 \beta$ at the same site during neuronal migration.

In this study, we also found that a key consequence of LKB1mediated inactivation of GSK3 $\beta$ is the association of APC with the microtubule plus-ends (Fig. 6). It is well established that the APC binding to the plus-end is abolished by the phosphorylation

\footnotetext{
$\leftarrow$

(Figure legend continued.) lattice cultures were fixed at 2 DIV, and immunostained with antibodies against GFP, Glu-tubulin, and EB1. Small panels on the bottom are high-magnification images of the distal part of the leading process of the neurons in the upper panels. Scale bars: 2.5 $\mu \mathrm{m}$ (upper panels), $2 \mu \mathrm{m}$ (bottom panels). C, $\boldsymbol{D}$, Neocortical neurons derived from E14 mouse embryos were transfected with the GFP-expressing plasmid and LKB1 RNAi plasmid. The transfected neurons were then subjected to lattice cultures. $C$, At 2 DIV, neurons in the lattice cultures were fixed, and immunostained with antibodies against GFP, $\alpha$-tubulin, and APC. Small panels on the bottom are high-magnification images of the tip of the leading process of the neurons in the upper panels. Scale bars: $2.5 \mu \mathrm{m}$ (upper panels), $2 \mu \mathrm{m}$ (bottom panels). D, At 2 DIV, neurons in the lattice cultures were fixed, and immunostained with antibodies against GFP, Glu-tubulin, and EB1. Small panels on the bottom are high-magnification images of the distal part of the leading process of the neurons in the upper panels. The Glu-tubulin-labeled fibers indicated by an asterisk are scaffold fibers. Scale bars: $2.5 \mu \mathrm{m}$ (upper panels), $2 \mu \mathrm{m}$ (bottom panels).
}

of APC by GSK3 $\beta$ (Rubinfeld et al., 1996; Zumbrunn et al., 2001). We supposed that LKB1-induced inactivation of GSK3 $\beta$ enables APC to associate with the plus-ends of microtubules during neuronal migration. Importantly, we showed that interfering with APC binding to microtubules leads to a spatially restricted loss of microtubule stabilization at the leading process tip (Fig. 7). Further, the proper microtubule association of APC and the localized stabilization of microtubules are dependent on LKB1 and Ser9 phosphorylation of GSK3 $\beta$ (Fig. 6). We thus conclude that APC acts as an important component that transduces spatially regulated LKB1-GSK3 $\beta$ signaling to the localized control of microtubules at the leading process tip. It is noteworthy that LKB1 knockdown results not only in loss of microtubule stabilization, but also in an increase of the distance between the nucleus and centrosome $(\sim 6.9 \mu \mathrm{m}$ distance $)$ as compared to control $(\sim 2.1$ $\mu \mathrm{m}$ distance) (Fig. $1 B, C$ ). This would suggest that LKB1 regulates the nucleus-centrosome coupling (Tanaka et al., 2004). Interestingly, the abnormality in the nucleus-centrosome coupling was not observed in GSK3 $\beta$ S9A-introduced neurons $(\sim 1.5 \mu \mathrm{m}$ distance) (Fig. $4 B$ ). Thus, it is hypothesized that molecules other than GSK3 $\beta$ may relay the LKB1 signaling to regulate the nucleus-centrosome coupling in migrating neurons.

What is the basis for the microtubule stabilization via APC in the leading process tip? In migrating wound-edge fibroblasts, Glu-tubulin is detected within microtubules directed to the leading edge, and the Glu-tubulin accumulation is attributable to the microtubule capture at the cell cortex (Cook et al., 1998; Palazzo et al., 2001a; Gundersen, 2002; Wen et al., 2004). Noticeably, APC is expected to mediate the microtubule capture and stabilization in wound-edge fibroblasts. In fact, APC localizes at the stable microtubule plus-ends facing the leading edges (MimoriKiyosue et al., 2000; Wen et al., 2004) and associates with the plasma membranes via proteins such as $\beta$-catenin and Dlg, to anchor the microtubules to the cell cortex (Näthke et al., 1996; Etienne-Manneville et al., 2005; Mimori-Kiyosue et al., 2007). Further, it is known that APC can stabilize microtubules through direct interaction (Munemitsu et al., 1994; Smith et al., 1994; Zumbrunn et al., 2001). Considering that the disruption of proper plus-end-binding of APC in migrating neurons leads to microtubule destabilization at the leading process tip (Fig. 7), it is conceivable that the LKB1-GSK3 $\beta$-APC pathway in the leading process tip of migrating neurons promotes the microtubule capture at the leading edge cortex, which, in turn, stabilizes the microtubules in the process tip (Fig. $8 \mathrm{~A}$ ).

In addition, we provided here the first evidence that Ser9 phosphorylation of GSK $3 \beta$ and microtubule-binding of APC are critical for neuronal migration (Figs. 3, 7). Importantly, LKB1, Ser9 phosphorylation of GSK3 $\beta$, and proper APC binding to microtubules are all required for directional centrosomal movement (Figs. 1, 5, 7). It has been suggested that in various types of cells (e.g., fibroblasts, primary astrocytes, MDCK cells) dynein/ dynactin complex at the cell cortex generates the traction force to pull the stabilized microtubules captured at the cell cortex (Busson et al., 1998; Etienne-Manneville and Hall, 2001; Palazzo et al., 2001b; Dujardin and Vallee, 2002). In mitotic MDCK cells, this leads to repositioning of the centrosome and then contributes to appropriate orientation of the mitotic spindle (Busson et al., 1998). In migrating wound-edge cells such as fibroblasts, the traction force induces reorientation of the centrosome toward leading edges and contributes to directional outgrowth of the cell protrusion (Etienne-Manneville and Hall, 2001; Palazzo et al., 2001b). Although an involvement of dynein/dynactin in the centrosomal forward movement in migrating neurons remains to be 
A

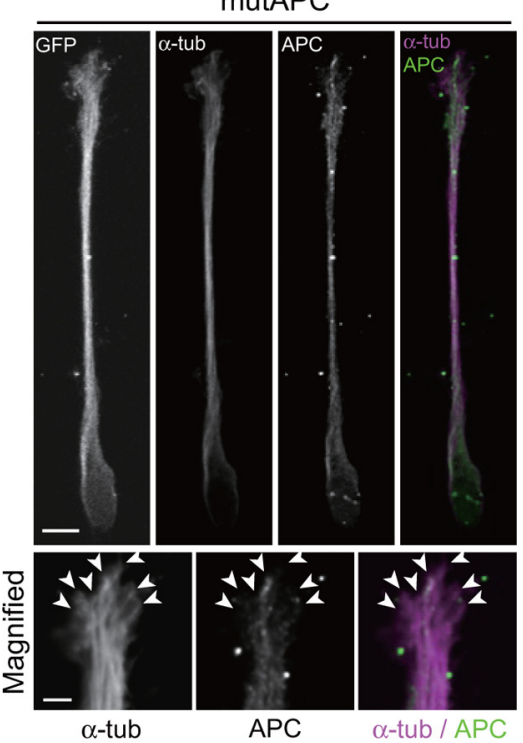

B

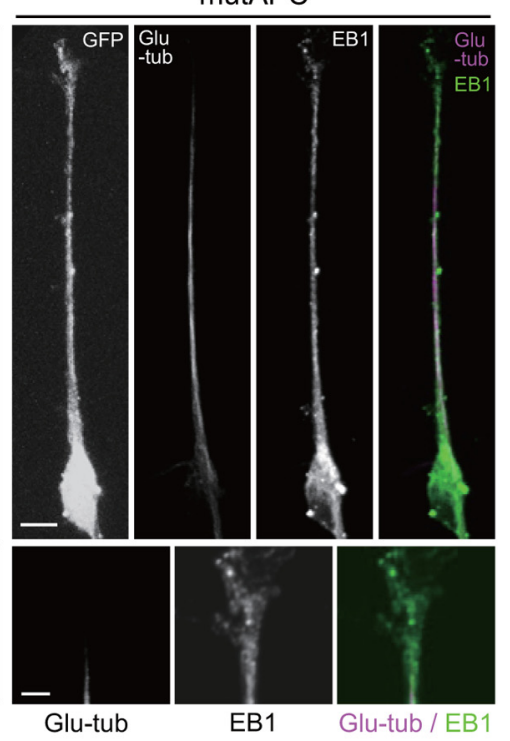

D
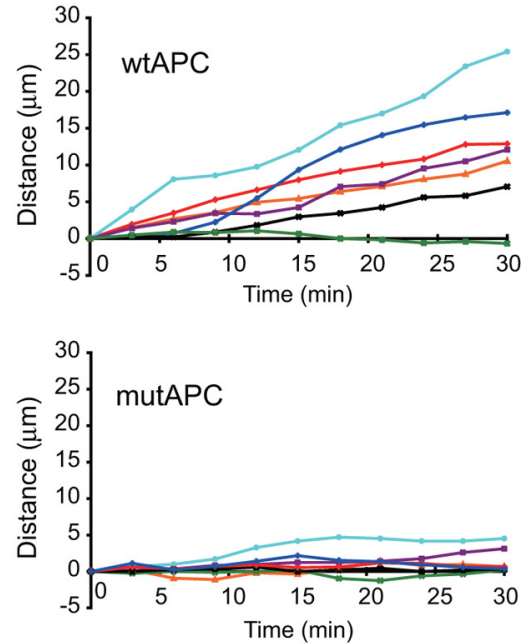

C
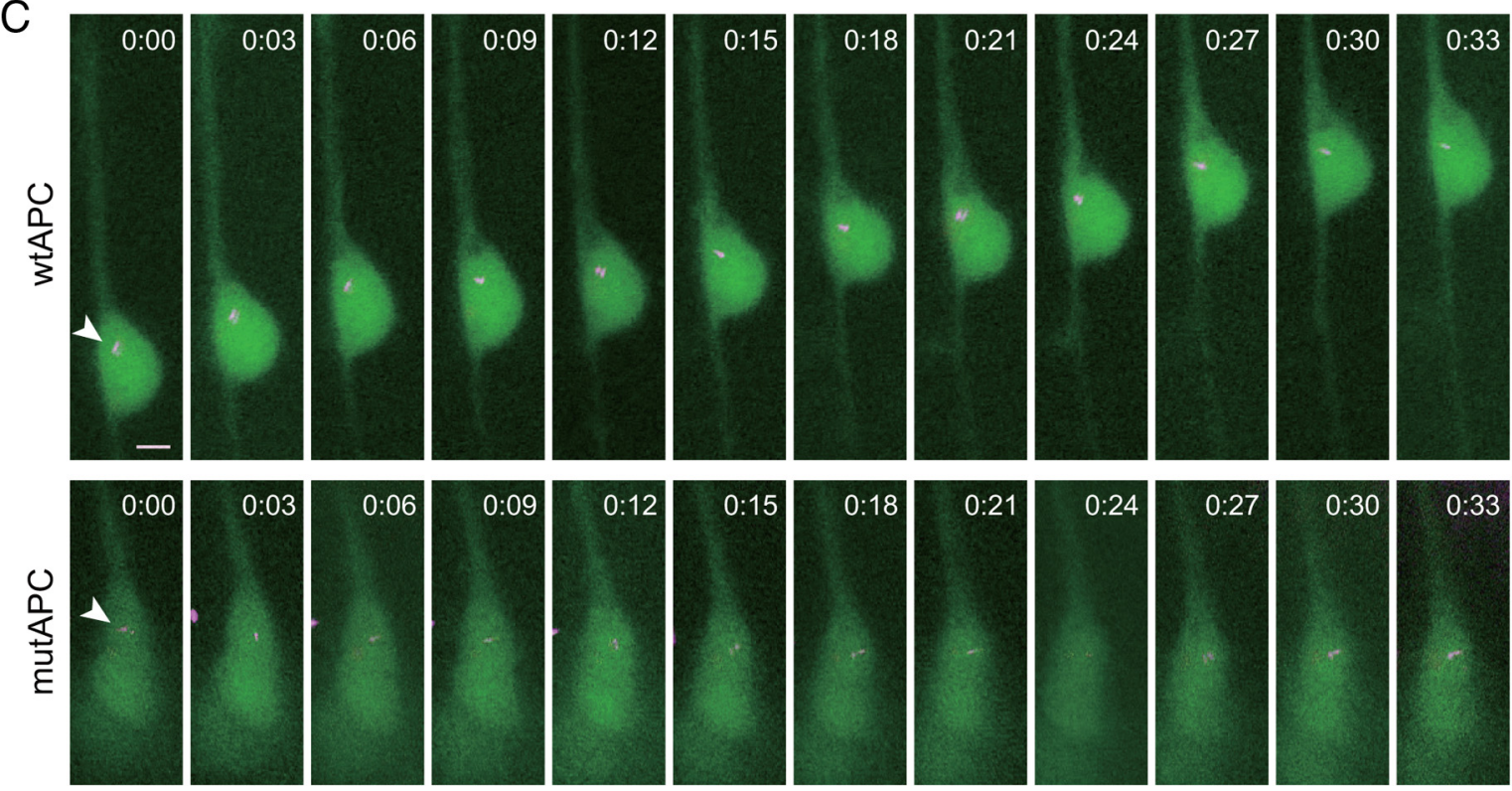

$E$
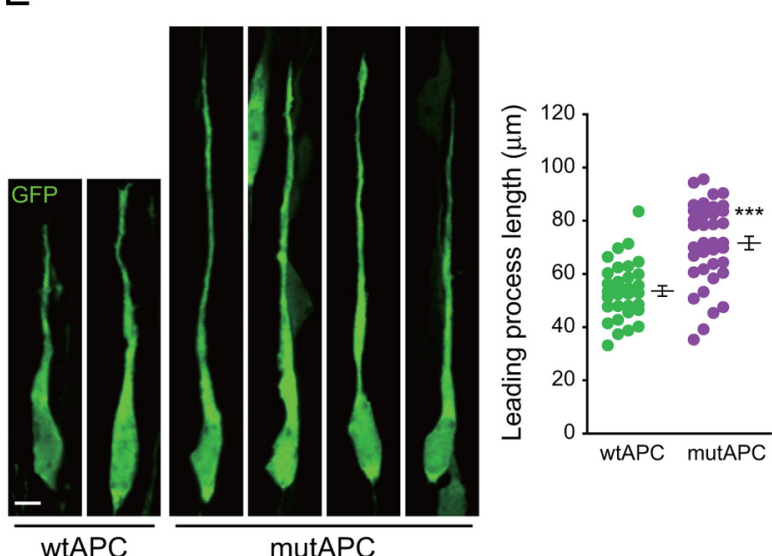

$\mathrm{F}$
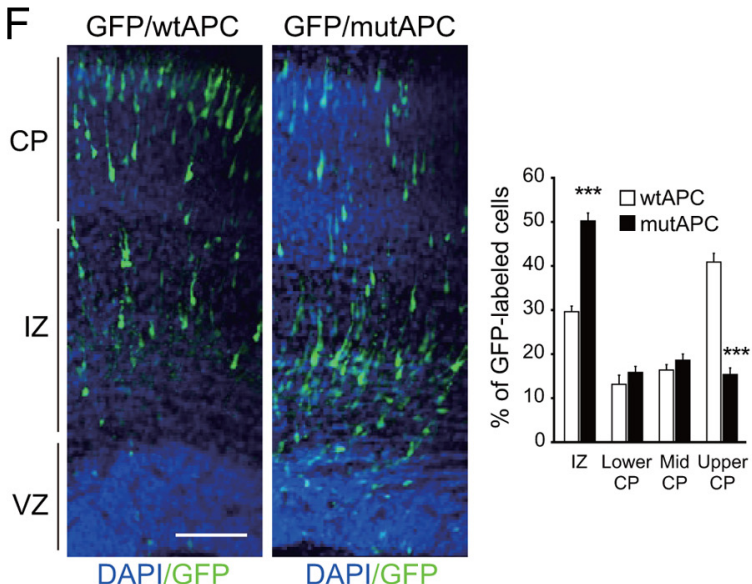

Figure 7. Proper localization of APC to microtubules is necessary for microtubule stabilization, centrosomal forward movement, and neuronal migration. $A, B$, Neocortical neurons derived from E14 mouse embryos were transfected with GFP-expressing plasmid and mutAPC-expressing plasmid. The transfected neurons were then subjected to lattice cultures. $\boldsymbol{A}$, At 2 DIV, neurons in the lattice cultures were fixed, and immunostained with antibodies against GFP, $\alpha$-tubulin, and APC. Small panels on the bottom are high-magnification images of the tip of the leading process of the neurons in the upper panels. Immunoreactivities for APC are hardly detected at the distal ends of microtubules indicated by arrowheads. Scale bars: $5 \mu \mathrm{m}$ (upper panels), (Figure legend continues.) 

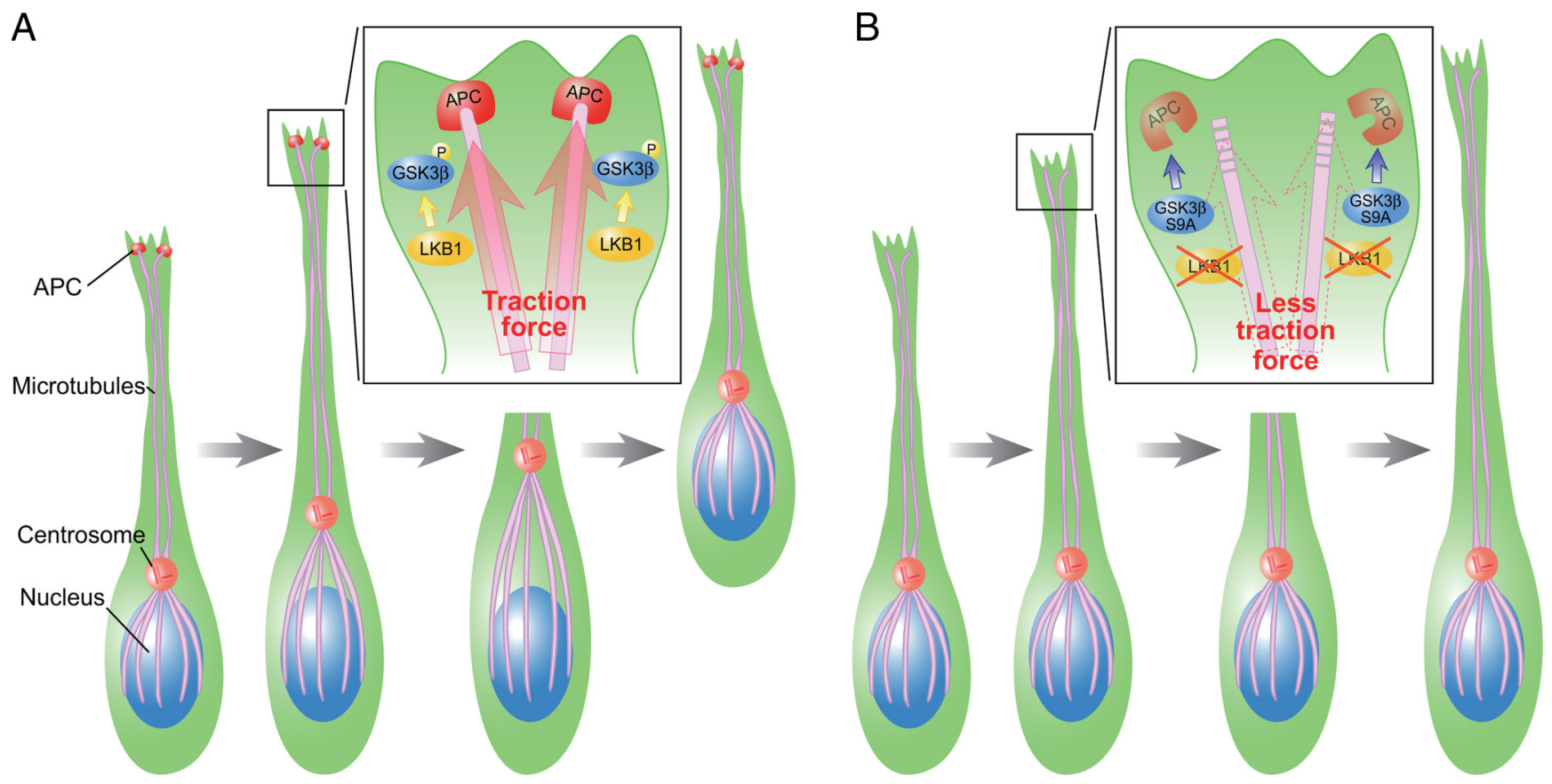

Figure 8. A model for a role of LKB1-GSK3 $\beta$-APC pathway in centrosomal forward movement. $A$, In migrating neurons, LKB1 mediates Ser9 phosphorylation and inactivation of GSK3 $\beta$ in the leading process tip, and this enables APC, a microtubule plus-end protein, to bind to the microtubule ends, anchor them to the leading edge cortex, and stabilize them. Certain motor proteins such as dynein/dynactin (not shown) at the cell cortex provide a traction force on the microtubules and pull the centrosome up in the leading process. $\boldsymbol{B}$, When either Ser9 phosphorylation of GSK3 $\beta$ or APC binding to the microtubule ends is disrupted, microtubules in the leading process tip is destabilized, probably due to impairment of microtubule capture at the cell cortex. This may lead to less traction force provided on the microtubules and results in impairment of centrosomal upward movement and elongation of the leading process.

elucidated, it is hypothesized that the stabilized microtubules anchored to the cell edge via APC may be pulled by dynein/dynactin at the leading edge of migrating neurons, leading to unidirectional and continuous movement of the centrosome (Fig. $8 \mathrm{~A}$ ). In neurons in which either Ser9 phosphorylation of GSK3 $\beta$ or proper localization of APC is impaired, anchorage of the microtubule plus-ends to the leading edge is disrupted, and consequently, the traction force to pull the centrosome forward may become reduced (Fig. $8 \mathrm{~B}$ ).

In this study, we also establish the in vivo importance of LKB1GSK3 $\beta$ signaling in neuronal migration. Previous knock-out

\section{$\leftarrow$}

(Figure legend continued.) $2 \mu \mathrm{m}$ (bottom panels). B, At 2 DIV, neurons in the lattice cultures were fixed, and immunostained with antibodies against GFP, Glu-tubulin, and EB1. Small panels on the bottom are high-magnification images of the distal part of the leading process of the neurons in the upper panels. Scale bars: $5 \mu \mathrm{m}$ (upper panels), $2 \mu \mathrm{m}$ (bottom panels). C, Either the wild-type APC (wtAPC)- or mutAPC-expressing plasmid was transfected into neocortical neurons derived from E14 mouse embryos, together with the plasmids encoding GFP and DsRed2-Centrinll. Transfected neurons were then subjected to lattice cultures. At 2 DIV, neurons apposed to fiber fascicles in lattice cultures were monitored by using 3 min time-lapse intervals. Time is denoted as hours:minutes in the top of each panel. The position of the centrosome is indicated by an arrow in the panels of time $=0: 00$. Scale bar, $5 \mu \mathrm{m}$. $\boldsymbol{D}$, The graphs show the representative centrosomal tracings in wtAPC-expressing cells (top) and mutAPC-expressing cells (bottom). $\boldsymbol{E}, \boldsymbol{F}$, The plasmid expressing either wtAPC or mutAPC was electroporated into E14 embryos together with GFP-expressing plasmid. Brains were fixed at E17, and the brain sections were immunostained with anti-GFP antibody. Nuclei were stained with DAPI. $\boldsymbol{E}$, The leading process length of GFP-labeled migrating neurons in the upper $\mathrm{IZ}$ and lower $\mathrm{CP}$ was analyzed and plotted as the mean \pm SEM $(n=32$ cells from 4 embryos, and 38 cells from 5 embryos for wtAPC and mutAPC, respectively). Dots in the graph correspond to the leading process length of individual neurons. ${ }^{* * *} p<0.001$ versus wtAPC by two-tailed Welch's $t$ test. Scale bar, $5 \mu \mathrm{m}$. $\boldsymbol{F}$, The percentage of GFP-labeled cells in the IZ and CP was calculated and plotted as the mean \pm SEM $[n=4$ embryos (total 1480 neurons analyzed) for wTAPC at E17, and 5 embryos (total 831 neurons analyzed) for mutAPC]. ${ }^{* * *} p<0.001$ versus wtAPC by two-tailed Student's $t$ test. Scale bar, $100 \mu \mathrm{m}$. study of LKB1 in the developing neocortex has reported that genetic loss of LKB1 did not appear to affect neuronal migration (Barnes et al., 2007). It is noteworthy that acute knockdown of genes using RNAi and in utero electroporation in the developing neocortex has been shown to circumvent the molecular compensatory responses that may be activated in genetic knock-out, as demonstrated in the case of Doublecortin and MARK2 (Bai et al., 2003; Sapir et al., 2008). Hence, although neuronal migration defects have not been reported in LKB1 mutant mice, it is conceivable that the acute reduction of LKB1 has enabled us to dissect out its function in neuronal migration. Regarding GSK $3 \beta$, several recent studies have reported that GSK3 $\beta$ acts as a regulator for proliferation of neural progenitors (Kim et al., 2009; Mao et al., 2009) and polarization of differentiating neurons (Shi et al., 2004; Jiang et al., 2005; Yoshimura et al., 2005). On these bases and the present study, proper regulation of GSK3 $\beta$ appears to govern various aspects of neuronal development.

In sum, the present study uncovers a novel spatially localized signaling cascade that impacts the polarized control of the microtubules and centrosomal forward movement, a key step for neuronal migration. These findings underscore the importance of understanding spatially localized signaling pathways to decipher the complex molecular mechanisms underlying neuronal migration.

\section{References}

Asada N, Sanada K, Fukada Y (2007) LKB1 regulates neuronal migration and neuronal differentiation in the developing neocortex through centrosomal positioning. J Neurosci 27:11769-11775.

Bai J, Ramos RL, Ackman JB, Thomas AM, Lee RV, LoTurco JJ (2003) RNAi reveals doublecortin is required for radial migration in rat neocortex. Nat Neurosci 6:1277-1283.

Barnes AP, Lilley BN, Pan YA, Plummer LJ, Powell AW, Raines AN, Sanes JR, Polleux F (2007) LKB1 and SAD kinases define a pathway required for the polarization of cortical neurons. Cell 129:549-563. 
Bienz M (2002) The subcellular destinations of APC proteins. Nat Rev Mol Cell Biol 3:328-338.

Busson S, Dujardin D, Moreau A, Dompierre J, De Mey JR (1998) Dynein and dynactin are localized to astral microtubules and at cortical sites in mitotic epithelial cells. Curr Biol 8:541-544.

Cook TA, Nagasaki T, Gundersen GG (1998) Rho guanosine triphosphatase mediates the selective stabilization of microtubules induced by lysophosphatidic acid. J Cell Biol 141:175-185.

Dujardin DL, Vallee RB (2002) Dynein at the cortex. Curr Opin Cell Biol 14:44-49.

Etienne-Manneville S, Hall A (2001) Integrin-mediated activation of Cdc42 controls cell polarity in migrating astrocytes through PKC $\zeta$. Cell 106:489-498.

Etienne-Manneville S, Hall A (2003) Cdc42 regulates GSK-3 $\beta$ and adenomatous polyposis coli to control cell polarity. Nature 421:753-756.

Etienne-Manneville S, Manneville JB, Nicholls S, Ferenczi MA, Hall A (2005) $\mathrm{Cdc4} 2$ and Par6-PKC $\zeta$ regulate the spatially localized association of Dlg1 and APC to control cell polarization. J Cell Biol 170:895-901.

Goldstein B, Macara IG (2007) The PAR proteins: fundamental players in animal cell polarization. Dev Cell 13:609-622.

Gundersen GG (2002) Evolutionary conservation of microtubule-capture mechanisms. Nat Rev Mol Cell Biol 3:296-304.

Gundersen GG, Kalnoski MH, Bulinski JC (1984) Distinct populations of microtubules: tyrosinated and nontyrosinated alpha tubulin are distributed differently in vivo. Cell 38:779-789.

Hatten ME (1990) Riding the glial monorail: a common mechanism for glial-guided neuronal migration in different regions of the developing mammalian brain. Trends Neurosci 13:179-184.

Jiang H, Guo W, Liang X, Rao Y (2005) Both the establishment and the maintenance of neuronal polarity require active mechanisms: critical roles of GSK-3 $\beta$ and its upstream regulators. Cell 120:123-135.

Jimbo T, Kawasaki Y, Koyama R, Sato R, Takada S, Haraguchi K, Akiyama T (2002) Identification of a link between the tumour suppressor APC and the kinesin superfamily. Nat Cell Biol 4:323-327.

Kemphues KJ, Priess JR, Morton DG, Cheng NS (1988) Identification of genes required for cytoplasmic localization in early C. elegans embryos. Cell 52:311-320.

Kim WY, Wang X, Wu Y, Doble BW, Patel S, Woodgett JR, Snider WD (2009) GSK-3 is a master regulator of neural progenitor homeostasis. Nat Neurosci 12:1390-1397.

Lambert de Rouvroit C, Goffinet AM (2001) Neuronal migration. Mech Dev 105:47-56.

Lizcano JM, Göransson O, Toth R, Deak M, Morrice NA, Boudeau J, Hawley SA, Udd L, Mäkelä TP, Hardie DG, Alessi DR (2004) LKB1 is a master kinase that activates 13 kinases of the AMPK subfamily, including MARK/ PAR-1. EMBO J 23:833-843.

Mao Y, Ge X, Frank CL, Madison JM, Koehler AN, Doud MK, Tassa C, Berry EM, Soda T, Singh KK, Biechele T, Petryshen TL, Moon RT, Haggarty SJ, Tsai LH (2009) Disrupted in schizophrenia 1 regulates neuronal progenitor proliferation via modulation of GSK3 $\beta / \beta$-catenin signaling. Cell 136:1017-1031.

Mimori-Kiyosue Y, Shiina N, Tsukita S (2000) Adenomatous polyposis coli (APC) protein moves along microtubules and concentrates at their growing ends in epithelial cells. J Cell Biol 148:505-518.

Mimori-Kiyosue Y, Matsui C, Sasaki H, Tsukita S (2007) Adenomatous polyposis coli (APC) protein regulates epithelial cell migration and morphogenesis via PDZ domain-based interactions with plasma membranes. Genes Cells 12:219-233.

Munemitsu S, Souza B, Müller O, Albert I, Rubinfeld B, Polakis P (1994) The APC gene product associates with microtubules in vivo and promotes their assembly in vitro. Cancer Res 54:3676-3681.

Näthke IS, Adams CL, Polakis P, Sellin JH, Nelson WJ (1996) The adenomatous polyposis coli tumor suppressor protein localizes to plasma membrane sites involved in active cell migration. J Cell Biol 134:165-179.

Nichols AJ, Carney LH, Olson EC (2008) Comparison of slow and fast neo- cortical neuron migration using a new in vitro model. BMC Neurosci 9:50.

Palazzo AF, Cook TA, Alberts AS, Gundersen GG (2001a) mDia mediates Rho-regulated formation and orientation of stable microtubules. Nat Cell Biol 3:723-729.

Palazzo AF, Joseph HL, Chen YJ, Dujardin DL, Alberts AS, Pfister KK, Vallee RB, Gundersen GG (2001b) Cdc42, dynein, and dynactin regulate MTOC reorientation independent of Rho-regulated microtubule stabilization. Curr Biol 11:1536-1541.

Rakic P (1990) Principles of neural cell migration. Experientia 46:882-891. Rubinfeld B, Albert I, Porfiri E, Fiol C, Munemitsu S, Polakis P (1996) Binding of GSK $3 \beta$ to the APC- $\beta$-catenin complex and regulation of complex assembly. Science 272:1023-1026.

Sanada K, Tsai LH (2005) G protein $\beta \gamma$ subunits and AGS3 control spindle orientation and asymmetric cell fate of cerebral cortical progenitors. Cell 122:119-131

Sapir T, Sapoznik S, Levy T, Finkelshtein D, Shmueli A, Timm T, Mandelkow EM, Reiner O (2008) Accurate balance of the polarity kinase MARK2/ Par-1 is required for proper cortical neuronal migration. J Neurosci 28:5710-5720.

Shelly M, Cancedda L, Heilshorn S, Sumbre G, Poo MM (2007) LKB1/ STRAD promotes axon initiation during neuronal polarization. Cell 129:565-577.

Shi SH, Cheng T, Jan LY, Jan YN (2004) APC and GSK-3 $\beta$ are involved in mPar3 targeting to the nascent axon and establishment of neuronal polarity. Curr Biol 14:2025-2032.

Smith KJ, Levy DB, Maupin P, Pollard TD, Vogelstein B, Kinzler KW (1994) Wild-type but not mutant APC associates with the microtubule cytoskeleton. Cancer Res 54:3672-3675.

Solecki DJ, Model L, Gaetz J, Kapoor TM, Hatten ME (2004) Par6 $\alpha$ signaling controls glial-guided neuronal migration. Nat Neurosci 7:1195-1203.

Solecki DJ, Trivedi N, Govek EE, Kerekes RA, Gleason SS, Hatten ME (2009) Myosin II motors and F-actin dynamics drive the coordinated movement of the centrosome and soma during CNS glial-guided neuronal migration. Neuron 63:63-80.

Tanaka T, Serneo FF, Higgins C, Gambello MJ, Wynshaw-Boris A, Gleeson JG (2004) Lis1 and doublecortin function with dynein to mediate coupling of the nucleus to the centrosome in neuronal migration. J Cell Biol 165:709-721.

Tsai LH, Gleeson JG (2005) Nucleokinesis in neuronal migration. Neuron 46:383-388.

Tsai JW, Bremner KH, Vallee RB (2007) Dual subcellular roles for LIS1 and dynein in radial neuronal migration in live brain tissue. Nat Neurosci 10:970-979.

Walsh CA, Goffinet AM (2000) Potential mechanisms of mutations that affect neuronal migration in man and mouse. Curr Opin Genet Dev 10:270-274.

Wen Y, Eng CH, Schmoranzer J, Cabrera-Poch N, Morris EJ, Chen M, Wallar BJ, Alberts AS, Gundersen GG (2004) EB1 and APC bind to mDia to stabilize microtubules downstream of Rho and promote cell migration. Nat Cell Biol 6:820-830.

Westermann S, Weber K (2003) Post-translational modifications regulate microtubule function. Nat Rev Mol Cell Biol 4:938-947.

Xie Z, Sanada K, Samuels BA, Shih H, Tsai LH (2003) Serine 732 phosphorylation of FAK by Cdk5 is important for microtubule organization, nuclear movement, and neuronal migration. Cell 114:469-482.

Yoshimura T, Kawano Y, Arimura N, Kawabata S, Kikuchi A, Kaibuchi K (2005) GSK-3 $\beta$ regulates phosphorylation of CRMP-2 and neuronal polarity. Cell 120:137-149.

Zhou FQ, Zhou J, Dedhar S, Wu YH, Snider WD (2004) NGF-induced axon growth is mediated by localized inactivation of GSK-3 $\beta$ and functions of the microtubule plus end binding protein APC. Neuron 42:897-912.

Zumbrunn J, Kinoshita K, Hyman AA, Näthke IS (2001) Binding of the adenomatous polyposis coli protein to microtubules increases microtubule stability and is regulated by GSK3 $\beta$ phosphorylation. Curr Biol 11:44-49. 